OPEN ACCESS

Edited by:

Steve Suib,

University of Connecticut,

United States

Reviewed by:

Roberto Millini,

Eni (Italy), Italy

Matteo Guidotti

Italian National Research Council

(CNR), Italy

Miguel Angel Centeno,

Instituto de Ciencia de Materiales de

Sevilla (ICMS), Spain

*Correspondence:

Ben Liu

ben.liu@njnu.edu.cn

$\mathrm{Jie} \mathrm{He}$

jie.he@uconn.edu

Specialty section:

This article was submitted to

Green and Sustainable Chemistry,

a section of the journal

Frontiers in Chemistry

Received: 28 November 2018

Accepted: 10 January 2019

Published: 30 January 2019

Citation:

Zhang L, Jin L, Liu B and He J (2019)

Templated Growth of Crystalline

Mesoporous Materials: From

Soft/Hard Templates to Colloidal

Templates. Front. Chem. 7:22.

doi: 10.3389/fchem.2019.00022

\section{Templated Growth of Crystalline Mesoporous Materials: From Soft/Hard Templates to Colloidal Templates}

\author{
Lei Zhang ${ }^{1,2}$, Lei $\mathrm{Jin}^{2}$, Ben Liu ${ }^{1 *}$ and Jie $\mathrm{He}^{2,3 *}$ \\ 1 Jiangsu Key Laboratory of New Power Batteries, Collaborative Innovation Center of Biomedical Functional Materials, School \\ of Chemistry and Materials Science, Nanjing Normal University, Nanjing, China, ${ }^{2}$ Department of Chemistry, University of \\ Connecticut, Mansfield, CT, United States, ${ }^{3}$ Institute of Materials Science, University of Connecticut, Mansfield, CT, \\ United States
}

Mesoporous non-siliceous materials, in particular mesoporous transition metal oxides ( $m$-TMOs), are of interest due to their fascinating electronic, redox, and magnetic properties for a wide range of applications in catalysis and energy storage. Control of the porosity (e.g., pore size, wall thickness, and surface area) and the crystalline degree (e.g., phase composition, crystallinity, and crystal grain size) of $m$-TMOs are critical for those applications. To crystallize TMOs, high temperature annealing is often needed to remove the amorphous defects and/or tune the compositions of different crystalline phases. This has brought many challenges to surfactant or block copolymer templates used in the process of evaporation-induced-self-assembly to prepare $m$-TMOs. In this review, we summarize the most recent achievements including the findings in our own laboratory on the use of organosilicate-containing colloids for the templated growth of mesoporous materials. We review a few key examples of preparing crystalline mesoporous oxides using different templating methods. The colloidal templating method by which mesoporous nanostructures can be stabilized up to $1,000^{\circ} \mathrm{C}$ is highlighted. The applications of $m$-TMOs and meso metal-oxide hybrids synthesized using organosilicate-containing colloidal templates in photocatalysis and high-temperature catalysis are also discussed.

Keywords: mesoporous materials, templates, transition metal oxides, nanoconfinement, polymer micelles, organosilicate

\section{INTRODUCTION}

Mesoporous materials are porous materials with periodically ordered pores in the range of 2 50 nm. They have large accessible surface areas and tunable pore sizes, which are of particular benefit for mass transport and dispersion of electrons/reactants. Therefore, mesoporous materials show great potential in electrocatalysis (Wu et al., 2012; Ren et al., 2013; Xin et al., 2018), photocatalysis (Li et al., 2007; Onozuka et al., 2012; Joo et al., 2013; Liu et al., 2015b) and energy storage, and conversion (Li et al., 2015, 2016; Fang et al., 2016; Le et al., 2017). Since ordered mesoporous silica such as MCM-41 were discovered in 1992 (Kresge et al., 1992), extensive efforts have been devoted to the development of many other mesoporous silica such as SBA-15/16 (Zhao et al., 1998a,b; Sakamoto et al., 2000), KIT-6 (Kleitz et al., 2003), AMS (Qiu and Che, 2011; Han and Che, 2013), and FDU-12 (Fan et al., 2003, 2005). These mesoporous silica with ordered and 
interconnected nanopores as well as excellent thermal stability have been broadly used as support for metal nanocatalysts. Other than mesoporous silica, there has been a substantial amount of interest in mesoporous transition metal oxides ( $m$-TMOs) due to their unique $d$-shell electrons, resulting in a redox active surface on top of the nanosized pores (Schüth, 2001). Compared to amorphous mesoporous silica, $m$-TMOs exhibit enhanced electronic and optical properties (Kondo and Domen, 2008), which have been proven to be essential in the applications such as photocatalysis (Kuo et al., 2015; Liu et al., 2015b), electrocatalysis (Burke et al., 2015; Song et al., 2018), and battery materials (Su et al., 2016; Zheng et al., 2018).

The crystallinity of $m$-TMOs is of critical importance for some of their applications. Since high-temperature annealing is the most common way to increase the crystallinity and tune the crystalline phases of $m$-TMOs (Lee et al., 2008; Zhang et al., 2010; Liu et al., 2015b), how to stabilize porous frameworks under high temperature is the key to producing highly crystalline $m$-TMOs. Using photocatalysis as an example, $\mathrm{TiO}_{2}$ is one of the most wellstudied photocatalysts. The low-crystalline $\mathrm{TiO}_{2}$ with amorphous domains is known to effectively trap photo-excited electrons and holes that lower the overall utilization of photoexcitation (Ohtani et al., 1997). $\mathrm{TiO}_{2}$ has two common crystalline structures, including rutile and anatase. As a photocatalyst, anatase shows much better activity compared to rutile. Interestingly, $\mathrm{TiO}_{2}$ with mixed phases outperforms both pure phases (Cong and Xu, 2011; Zhao et al., 2013; Siah et al., 2016). P25 (Degussa) consisting of $\sim 80 \%$ of anatase and $\sim 20 \%$ of rutile has often been used as a benchmark $\mathrm{TiO}_{2}$ photocatalyst. Since there is a type II band alignment of $\sim 0.4 \mathrm{eV}$ (the energy of valance band) (Scanlon et al., 2013), $\mathrm{TiO}_{2}$ with a mixture of phases shows enhanced charge separation efficiency at the interface of rutile and anatase (Kawahara et al., 2002; Miyagi et al., 2004). Converting anatase or non-crystalline to rutile $\mathrm{TiO}_{2}$ requires high-temperature annealing, e.g., at $800^{\circ} \mathrm{C}$, although the rutile $\mathrm{TiO}_{2}$ is more stable. When the annealing is carried out in a mesoporous $\mathrm{TiO}_{2}$, the collapse of the porous framework occurs before the phase transition due to the overgrowth of crystal grains (Schüth, 2001; Yun et al., 2001). Another example is the formation of crystalline mixed oxides in order to control the optical properties. Carter et al. have proposed the $\mathrm{MnO}: \mathrm{ZnO}$ alloys that potentially shift the band energy of MnO dramatically (Kanan and Carter, 2012, 2013). $\mathrm{MnO}$ as an n-type semiconductor has a large bandgap of $4.0 \mathrm{eV}$ but, when forming alloys with $\mathrm{ZnO}$, its band energy can be shifted largely to a bandgap of $2.6 \mathrm{eV}$, which is potentially useful for photocatalytic water splitting or $\mathrm{CO}_{2}$ reduction. The formation of mixed oxides of $\mathrm{MnO}: \mathrm{ZnO}$ needs high-temperature treatment at $700^{\circ} \mathrm{C}$ (Song et al., 2015). The synthesis of such binary or ternary oxides (e.g., copper tungstate and perovskites) in mesoporous form will be very difficult because of the poor thermal stability of porous frameworks. Overall, the control of crystallinity and crystal phases is critical in tuning the physicochemical properties of $m$-TMOs.

In this review, we summarize the synthetic methods in recent years for the preparation of highly crystalline $m$-TMOs. The synthesis will be discussed by classifying the synthetic methods based on the templates (Figure 1), including hard templates, soft templates, and colloidal templates. There are a number of excellent review papers on the synthesis of mesoporous materials such as $\mathrm{TiO}_{2}$ ( $\mathrm{Li}$ et al., 2013), non-siliceous oxides ( $\mathrm{Gu}$ and Schuth, 2014), and metal oxides (Ren et al., 2012) by mainly softtemplating and hard-templating methods. We intend to highlight a few key examples in control of the crystallinity of $m$-TMOs by different methods, with a focus on the findings in our own laboratory on the use of organosilicate-containing colloids for the templated growth of mesoporous materials. The applications of colloidal-templated porous oxides and metal-oxide hybrids in photocatalysis will be included. At the end of this review, we include a short perspective in this area. We hope that this review will help readers to understand the challenges and solutions in the rational design and application of crystalline $m$-TMOs.

\section{HARD-TEMPLATING METHOD}

The hard-templating method, also known as nanocasting, provides the most accessible strategy to synthesize crystalline mesoporous materials. Nanocasting is to make use of a rigid mold with defined porous structures on the nanometer scale where the target materials or their precursors are added to fill the pore of the mode, and the primary mold is subsequently removed after the formation of target materials (Lu and Schüth, 2006). In detail, nanocasting of $m$-TMO includes three steps: (1) synthesis of mesoporous replicas (e.g., silica, carbons, and aluminates); (2) infiltration of metal precursors and further decomposition to form crystalline materials; and (3) removal of the hard template to release the pores. Upon removal of the mold, the yielded $m$-TMO will replicate the complementary mesostructures of the hard template. For instance, silica templates equipped with ordered cylindrical channels can produce nanowires or nanoarrays ( $\mathrm{Lu}$ and Schüth, 2005), while the template with spherical pores can prepare the nanosphere arrays (Lu and Schüth, 2006), and the template with bicontinuous pores results in bicontinuous mesostructured duplicates with periodically and helically twisted nanowires (Yang and Zhao, 2005). The framework thickness of the mesoporous silica is usually in the range of $2-11 \mathrm{~nm}$; thus, the pore size of derived replicas of $m$-TMO is also in the same range (Schüth, 2001).

Ideally, all crystalline mesoporous materials can be synthesized using the hard-templating method if the corresponding metal precursors can be filled into the pore of the mold. So far, among numerous hard templates, mesoporous silica (e.g., SBA-15 and KIT-6) are commonly used for the preparation of mesoporous materials due to their diverse pore architectures and extremely uniform pore size/size distribution. SBA-15 has uniform hexagonal pores with the pore diameter in the range of 5-15 nm (Zhao et al., 1998a,b; Sakamoto et al., 2000). KIT-6 shows a bicontinuous structure as a gyroid cubic symmetry Ia3d with a pore diameter in the range of 4-12 $\mathrm{nm}$ (Kleitz et al., 2003). When using mesoporous silica as a template, the removal of silica to release the pore usually relies on the etching by concentrated $\mathrm{NaOH}$ or HF. One can also consider the use of mesoporous carbon as a template to prepare $m$-TMO, where the carbon template can simply be oxidized by low-temperature annealing 


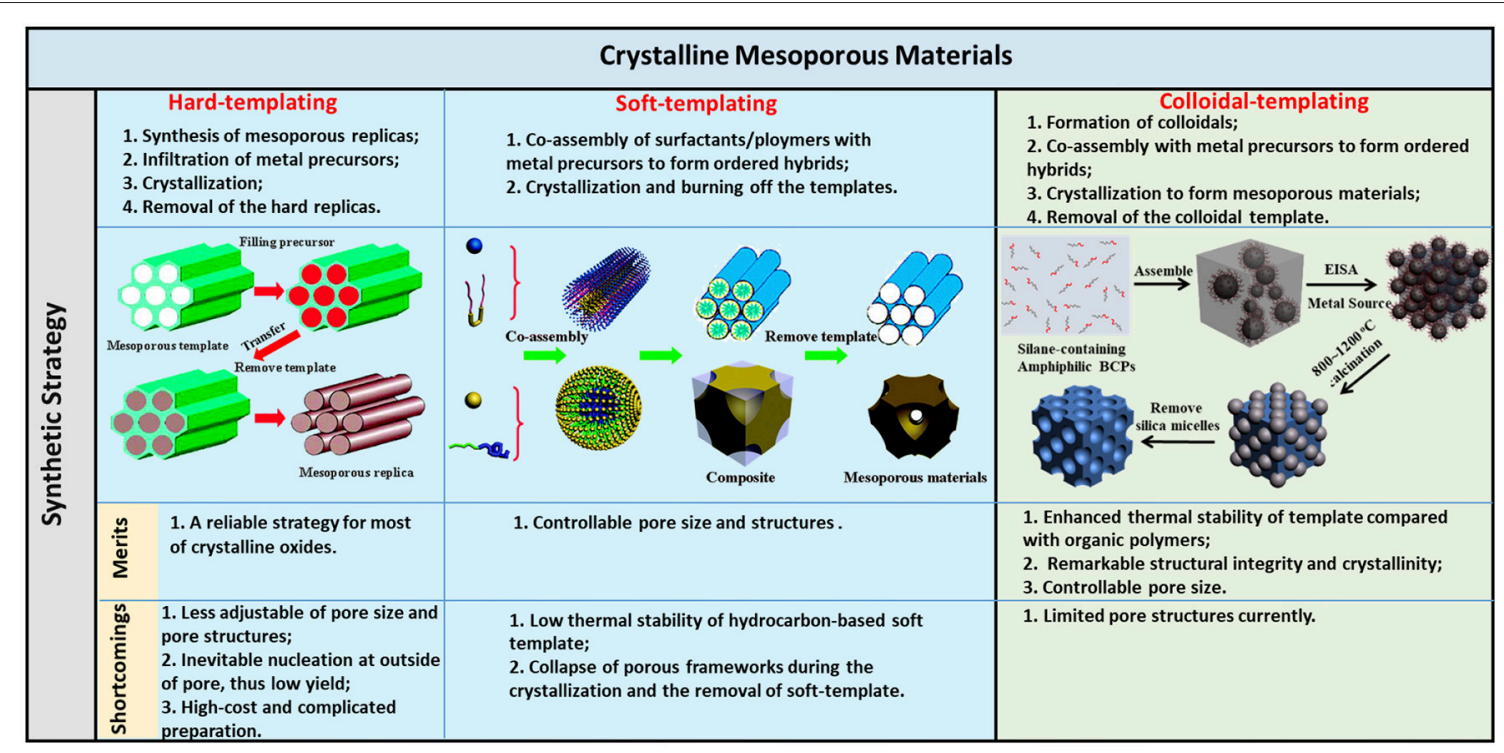

FIGURE 1 | |llustration of the synthetic methods/procedures of crystalline mesoporous materials and the merits/shortcomings of the three methods. Reprinted with permission from Gu and Schuth (2014) and Liu et al. (2015b). Copyright 2015 American Chemical Society and Copyright 2014 Royal Society of Chemistry.

in air (Lu et al., 2002; Roggenbuck and Tiemann, 2005; Polarz et al., 2007; Liang et al., 2008).

Given the hard templates that can support and confine the grain growth of TMOs, the crystalline phases and pore features of metal oxides can be rationally designed. Taking manganese oxides as an example, Bruce's group synthesized mesoporous $\beta-\mathrm{MnO}_{2}, \mathrm{Mn}_{2} \mathrm{O}_{3}$, and $\mathrm{Mn}_{3} \mathrm{O}_{4}$ by high-temperature calcination at different temperatures or in the assistance of $\mathrm{H}_{2}$, using KIT-6 as the hard template (Jiao and Bruce, 2007; Jiao et al., 2007). All the materials possessed similar mesoporous frameworks and well-controlled crystalline phases of Mn oxides (Figures 2A-C). Similarly, iron oxides (Jiao et al., 2006) and cobalt oxides (Jiao et al., 2005a) with different crystalline phases were also obtained using the same strategy (Ren et al., 2009). Furthermore, bicontinuous mesoporous nanochannels of KIT-6 can also be utilized to tailor the final porosity of the materials. By selectively filling in different sets of nanochannels, mesoporous oxides with different pore sizes and even pore hierarchies (macropore, mesopore, and micropore) were successfully synthesized (Figures 2D-F) (Ren et al., 2013). The hard-templating synthesis of mesoporous materials is also extendable to metal sulfides and phosphides (Fu et al., 2016; Jin et al., 2017).

The hard-templating method shows limited control over the mesoporous structures but, in KIT-6 template, the distribution, and adjustable ratio of the two different pores can be achieved by hydrothermal synthetic conditions (Figure 3) (Jiao et al., 2008; Ren et al., 2010). Using mesoporous $\mathrm{NiO}$ as an example, an alcoholic solution of $\mathrm{Ni}\left(\mathrm{NO}_{3}\right)_{2}$ was mixed with KIT-6 and then redispersed in hexane to achieve a very high degree of pore filling. Followed by calcination at $550^{\circ} \mathrm{C}$ and removal of KIT- 6 via etching with $\mathrm{NaOH}$, mesoporous $\mathrm{NiO}$ with a specific surface area of $108.6 \mathrm{~m}^{2} \mathrm{~g}^{-1}$ can be synthesized. KIT-6 has two sets of pores

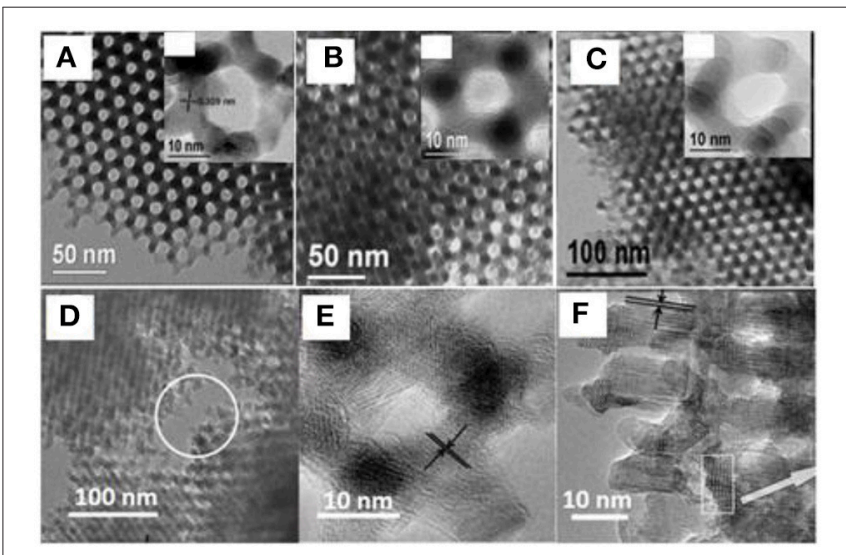

FIGURE 2 | Control of crystallinity and mesostructures of Mn oxides. TEM images of (A) mesoporous $\beta-\mathrm{MnO}_{2}$, (B) $\mathrm{Mn}_{2} \mathrm{O}_{3}$, and (C) $\mathrm{Mn}_{3} \mathrm{O}_{4}$, and TEM images of (D-F) hierarchical porous $\mathrm{MnO}_{2}$ templated by $\mathrm{KIT}-6$. Reprinted with permission from Jiao and Bruce (2007), Jiao et al. (2007) and Ren et al. (2013) Copyright 2013 Nature Publishing Group and Copyright 2007 Willey VCH.

with bicontinous channels and the development of these channels varies along with the hydrothermal synthetic conditions of KIT-6. At a higher hydrothermal temperature $\left(>130^{\circ} \mathrm{C}\right)$, the existence of interconnected porous channels in KIT-6 favors complete growth of $\mathrm{NiO}$ across both sets of mesopores, leading to the formation of mesoporous $\mathrm{NiO}$ with a pore diameter $(\sim 3.3 \mathrm{~nm})$ similar to the wall thickness of KIT-6 (Figure 3). On the other hand, with less interconnected pores at a lower hydrothermal temperature, the growth of mesoporous $\mathrm{NiO}$ within only one set of mesopores was observed. The resultant mesoporous $\mathrm{NiO}$ has a pore size of $\sim 11 \mathrm{~nm}$, equivalent to the dimension of two walls plus the pore 


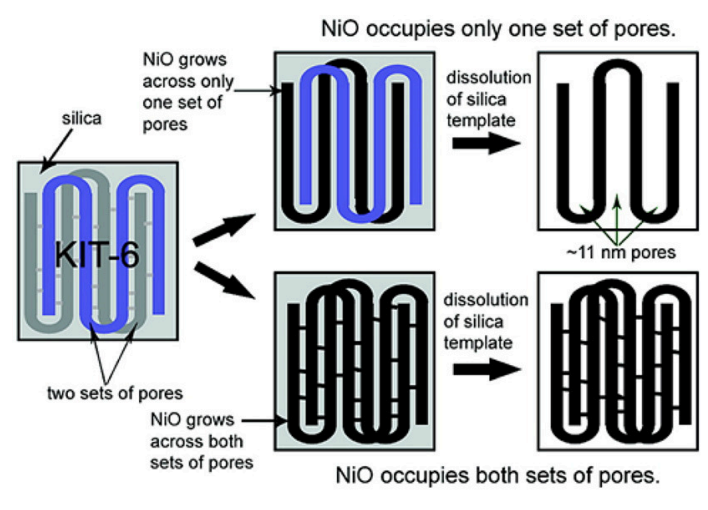

FIGURE 3 | Scheme illustrating the synthesis of $m$-TMO with two pore size distributions by using KIT-6 as the template. Reprinted with permission from Jiao et al. (2008). Copyright 2008 American Chemical Society.

size of KIT-6. Through this method, mesoporous $\beta-\mathrm{MnO}_{2}$ and $\mathrm{NiO}$ with large $(\sim 11 \mathrm{~nm})$ and small $(\sim 3.3 \mathrm{~nm})$ controllable pore sizes can be prepared.

Using SBA-15 as a template, $m$-TMO with ordered cylindrical channels can be prepared. Zhu et al. reported the highly crystalline $\mathrm{Cr}_{2} \mathrm{O}_{3}$ using aminopropyl-triethoxysilane (APTS)modified SBA-15 (Zhu et al., 2003). The formation of crystalline $\mathrm{Cr}_{2} \mathrm{O}_{3}$ needs calcination of the $\mathrm{Cr}_{2} \mathrm{O}_{3} @ S B A$ above $350^{\circ} \mathrm{C}$. After the removal of SBA-15, the mesoporous $\mathrm{Cr}_{2} \mathrm{O}_{3}$ possesses a specific surface area of $58.1 \mathrm{~m}^{2} \mathrm{~g}^{-1}$ and an average pore size of $3.4 \mathrm{~nm}$. Other mesoporous $m$-TMOs with cylindrical pores can be prepared through a similar route (Chen et al., 2003; Jiao et al., 2005b; Yue et al., 2005). Our group also demonstrated mesoporous $\mathrm{Co}_{3} \mathrm{O}_{4}, \mathrm{NiO}$, and their binary oxides by using bicontinuous KIT- 6 as the template. Through a solid-phase sulfurization method based on sulfur, bicontinuous mesoporous $\mathrm{CoS}_{2}, \mathrm{NiS}_{2}$, and their binary sulfides can be further synthesized (Jin et al., 2017). When using the double templates, more sophisticated nanostructures can be designed. For example, if coated with thin carbon on the SBA channels first, the further growth of metal oxides will be confined in the hollow carbon nanotubes within SBA-15. Zhao et al. showed the synthesis of a mesoporous $\mathrm{Co}_{3} \mathrm{O}_{4} @$ carbon nanotube using double templates of silica and carbon. The resultant oxidein-tube nanostructures possess a specific surface area up to $750 \mathrm{~m}^{2} \mathrm{~g}^{-1}$ and a controllable size of $\mathrm{Co}_{3} \mathrm{O}_{4}$ between 3 and $7 \mathrm{~nm}$.

The synthetic challenge of the hard-templating method is to completely fill the pores of the template due to the slow mass transfer at nanoscale (Yang and Zhao, 2005). Mostly, only small pieces of mesoporous replicas can be yielded. Despite functionalized mesoporous templates with binding groups (e.g., $-\mathrm{NH}_{2},-\mathrm{OH},-\mathrm{CH}=\mathrm{CH}_{2}$ ) (Zhu et al., 2003; Tian et al., 2004; Wang et al., 2005), metal precursors still inevitably nucleate and grow in the outside of template pores, in particular under high temperature. Additionally, the pore size of resultant replicas that is determined by the thickness of the framework is usually small and less adjustable in both SBA series and KIT-6. Meanwhile, the nanocasting method is high-cost and time-consuming (Lu and Schüth, 2005, 2006; Yang and Zhao, 2005).

\section{SOFT-TEMPLATING METHOD}

The soft-templating method usually uses unrigid nanostructures formed by intermolecular interaction force as templates. Followed by the deposition of inorganic sources on the surface and interior of the unrigid soft templates, the formation of mesostructures with defined pore structures and sizes can occur. Generally, soft templates include soft matter, including organic surfactants and/or block copolymers, that can interact with metal ions and self-assemble into liquid crystal phases to template the sol-gel process. The assembled process between metal ions and soft matter is driven by weak non-covalent bonds, such as hydrogen bonds, van der Waals forces, and electrostatic interaction. In addition, cooperative assembly between metal ions and soft matter is mostly involved in facilitating this process. Mesostructures with open pores can be obtained after the removal of soft template through calcination. The softtemplating method offers a large room of controllability in terms of the pore structures and pore sizes compared to the hardtemplating method. The key of the soft-templating method is the control over the sol-gel transition of precursors along the self-assembly of soft templates, i.e., surfactants/block copolymers (Meng et al., 2005; Li et al., 2013; Lokupitiya et al., 2016). By rationally tuning the cooperative assembly between precursors and templates, mesoporous materials can be obtained through either a solution-phase synthesis or evaporation-induced selfassembly (EISA) process. The first report on solution-phase synthesis of mesoporous oxides and phosphates by a similar route for MCM silica was in Huo et al. (1994). Due to the straightforwardness of tunability in size and self-assembled mesophases of surfactants/block copolymer, the soft-templating method has been widely used to tailor the mesoporous sizes and framework nanostructures of $m$-TMOs.

However, it is difficult to release mesopores by removing the surfactant because of the disruption and collapse of these porous frameworks during the crystallization of $m$-TMOs. Ying et al. first reported the ordered mesoporous $\mathrm{TiO}_{2}$ with open pores using titanium acetylacetonate tri-isopropoxide as $\mathrm{Ti}$ precursor and tetradecylphosphate as the template (Antonelli and Ying, 1995). The presence of acetylacetone slowed down the sol-gel transition, which allowed further interaction and co-assembly with $\mathrm{Ti}$ and the template. The resultant mesoporous $\mathrm{TiO}_{2}$ had a surface area of $200 \mathrm{~m}^{2} \mathrm{~g}^{-1}$ after calcination. Her group has extended this solution synthetic method to synthesize the ordered mesoporous $\mathrm{Nb}_{2} \mathrm{O}_{5}$ (Antonelli et al., 1996), $\mathrm{VO}_{\mathrm{x}}$ (Liu et al., 1997), and $\mathrm{ZrO}_{2}$ (Wong et al., 1997; Antonelli, 1999).

Yang and Zhao creatively developed Pluronic polymers (commercial PEO-PPO-PEO triblock copolymers) as soft templates in non-aqueous solution to synthesize a series of mesoporous silica and metal oxide, including $\mathrm{TiO}_{2}, \mathrm{ZrO}_{2}, \mathrm{Al}_{2} \mathrm{O}_{3}$, $\mathrm{Nb}_{2} \mathrm{O}_{5}, \mathrm{Ta}_{2} \mathrm{O}_{5}, \mathrm{WO}_{3}, \mathrm{HfO}_{2}, \mathrm{SnO}_{2}$, and mixed oxides $\mathrm{SiAlO}_{3.5}$, $\mathrm{SiTiO}_{4}, \mathrm{ZrTiO}_{4}, \mathrm{Al}_{2} \mathrm{TiO}_{5}$, and $\mathrm{ZrW}_{2} \mathrm{O}_{8}$ (Yang et al., 1998, 1999). Pluronic polymers have a long flexible poly(ethylene oxide) 
(PEO) chain that can coordinate with transitional metal ions via weak coordination bonds. The absence of water enabled a controllable sol-gel, i.e., hydrolysis and condensation of metal precursors. These resulted in the optimal co-assembly at inorganic/organic interfaces; therefore, Pluronic polymers further templated the growth of a number of $m$-TMOs with periodically ordered mesoporous nanostructures. Through EISA, Sanchez et al. used PEO-based surfactants (e.g., Pluronic F127, Pluronic P123, Brij 56, and Brij 58) as templates to synthesize highly ordered $m$-TMOs (Grosso et al., 2001; Crepaldi et al., 2003). However, since the conventional EISA method usually employed Pluronic polymers as templates, the pore size of $m$ TMOs is usually $<15 \mathrm{~nm}$ owing to the short hydrophobic PPO segments (Yang et al., 1998). Furthermore, both PEO and PPO polymers are thermally unstable. When annealing those $m$ TMOs to remove the template, the mesoporous nanostructures ineluctably undergo structural reconstruction for crystallization, leading to the overgrowth of crystal grains, and even collapse of mesoporous frameworks (Schüth, 2001; Yun et al., 2001).

More recently, Suib's group has developed a universal strategy to synthesize the thermally stable and crystalline $m$-TMOs (Poyraz et al., 2013). As illustrated in Figure 4A, the inverse micelle formed by Pluronic P123 served as a nanoreactor where the positively charged transition metal-oxo clusters were confined via hydrogen bonding interaction. As stabilized by P123, the uncontrolled aggregation of the clusters was reduced and hindered. The addition of 1-butanol, the solvent and interface modifier, further enhanced the physical barrier between the oxo-clusters and prevented condensation. The essential presence of nitric acid in this system enabled the penetration of the positively charged metal-oxo clusters into the micelles, simultaneously increasing the solubility of P123 and hydrating the core. Interestingly, the decomposition of the nitrate ions into nitric oxides $\left(\mathrm{NO}_{\mathrm{x}}\right)$ played a critical role in the consecutive heat treatment by adsorption onto metal oxo-clusters, therefore impeding the uncontrolled condensation. After the removal of P123 by calcination at different temperatures ranging from 150 to $550^{\circ}$, the $m$-TMOs were readily obtained with tunable pore size distribution. For example, the mesoporous $\mathrm{MnO}_{2}$ evolved from amorphous materials with higher specific surface area (255 $\mathrm{m}^{2} \mathrm{~g}^{-1}$ ) and smaller pore size $(2 \mathrm{~nm})$ at a low temperature of $150^{\circ}$ (Figures $4 \mathrm{~B}, \mathrm{C}$ ), to the ordered crystalline $\mathrm{Mn}_{2} \mathrm{O}_{3}$ with lower specific surface area $\left(35 \mathrm{~m}^{2} \mathrm{~g}^{-1}\right)$, and enlarged pore size $(12.3 \mathrm{~nm})$ at an elevated temperature of $550^{\circ}$ (Figures 4D,E). This method allows the general syntheses to a range of $\mathrm{m}$ TMOs including nickel, cobalt, iron oxides etc (Poyraz et al., 2013, 2014; Song et al., 2014; Jiang et al., 2015; Wasalathanthri et al., 2015). It is worth mentioning that the series of the $m$-TMOs are highly resistant to elevated temperatures up to $400 \sim 550^{\circ}$, showing superior thermal stability. This unique stable mesoporous structure affords the development of more efficient and heat-tolerant catalysts in high-temperature reactions (Poyraz et al., 2013; Lu et al., 2015; Vovchok et al., 2018).

As mentioned above, the crystallinity of $\mathrm{TiO}_{2}$ determines the surface amorphous defects that plays a critical role in photocatalysis. The high temperature treatment for a typical $m$ $\mathrm{TiO}_{2}$ obtained using Pluronic polymers as templates, usually causes structural collapse of the ordered mesoporous frameworks (Schüth, 2001; Yun et al., 2001). To solve the thermal stability challenges in soft-templating, Wiesner's group developed the combined assembly by soft and hard chemistries (so-called CASH, Figure 5a) method to fabricate mesoporous metal oxides $\left(m-\mathrm{TiO}_{2}\right.$ and $\left.m-\mathrm{Nb}_{2} \mathrm{O}_{5}\right)$ with excellent thermal stability and crystallinity (Lee et al., 2008). In the CASH method for the synthesis of $m-\mathrm{TiO}_{2}$ (Figure 5a), titanium chloride firstly reacted with titanium isopropoxide to form the metal oxide clusters and corresponding alkyl halide, which was added into the tetrahydrofuran (THF) solution of the block copolymer of poly(isoprene-block-ethylene oxide) (PI- $b$-PEO, $\mathrm{M}_{\mathrm{n}}=27,220 \mathrm{~g}$ $\mathrm{mol}^{-1}$ ). The hydrophilic PEO selectively bound the metal oxide sol, which generated an amorphous hybrid material under evaporation of a PI- $b$-PEO/metal oxide solution in air (the obtained hybrid in Figure 5b). Secondly, the as-made PI- $b$ $\mathrm{PEO} /$ metal oxide hybrids were annealed at $700^{\circ} \mathrm{C}$ in argon to achieve the highly crystalline materials. The metal oxide crystals nucleate, grow, and sinter into porous frameworks and PEO was removed by thermal decomposition, while the PI segments can be transformed in situ into a carbon scaffold inside the pore channels due to the existence of $s p^{2}$ hybridized carbon atoms in the PI segments of PI- $b$ $\mathrm{PEO}$ (the $\mathrm{TiO}_{2}-\mathrm{C}$ composite in Figure $5 \mathbf{c}$ ). The generated carbon scaffold acts as a hard template in situ to prevent the collapse of mesoporous frameworks while crystallizing under high temperature treatment $\left(700^{\circ} \mathrm{C}\right)$. Thus this generated highly crystalline $\mathrm{TiO}_{2}$ (Lee et al., 2008). Finally, the carbon inside $\mathrm{TiO}_{2}-\mathrm{C}$ composite could be removed by heating in air, yielding a well-organized, highly crystalline mesoporous $\mathrm{TiO}_{2}$ (Figure 5d) with a pore size of $23.6 \mathrm{~nm}$ and a specific surface area of $75 \mathrm{~m}^{2}$ $\mathrm{g}^{-1}$. Other polymers, like poly(ethylene oxide)- $b$-polystyrene (PEO- $b$-PS), which includes $s p^{2}$ hybridized carbon atoms and can be carbonized under inert atmosphere, potentially are useful to obtain highly crystalline $m$-TMOs using the CASH method (Zhang et al., 2011).

Other than carbonization thermally, Zhao's group developed a simple sulfuric acid $\left(\mathrm{H}_{2} \mathrm{SO}_{4}\right)$ carbonization method to generate a highly crystalline, ultra-stable ordered $m-\mathrm{TiO}_{2}$ by using Pluronic polymers (P123, F127, and F10) as templates (Figure 6A) (Zhang et al., 2010). In the process of EISA with titanium isopropoxide (TIPO), a mixture of $\mathrm{HCl}$, and $\mathrm{H}_{2} \mathrm{SO}_{4}$ as the acidic catalyst carbonized the polymer template to form amorphous carbon in the original pore channels. The in situ-formed carbon templates can stabilize the mesoporous structures during crystallization $\left(650^{\circ} \mathrm{C}\right)$ in $\mathrm{N}_{2}$. After burning off the carbon at $450^{\circ} \mathrm{C}$ in air, the resultant $m-\mathrm{TiO}_{2}$ with a specific surface area of 193 $\mathrm{m}^{2} \mathrm{~g}^{-1}$ and a pore size of $4.6 \mathrm{~nm}$ was generated, which also possessed a high crystallinity of anatase and thermal stability (Figures 6B,C). To keep the structural order of $m$-TMOs, Zhou et al. synthesized the well-ordered mesoporous $m-\mathrm{TiO}_{2}$ with improved crystallinity and remarkably thermal stability through the EISA method assisted with encircling ethylenediamine (EN) protectors to retain the mesoporous structure (Zhou et al., 2011). The EN species could tightly interact and bind on the surface of $\mathrm{TiO}_{2}$ while prohibiting undesirable grain growth and structure transformation during calcination. Thus, the 

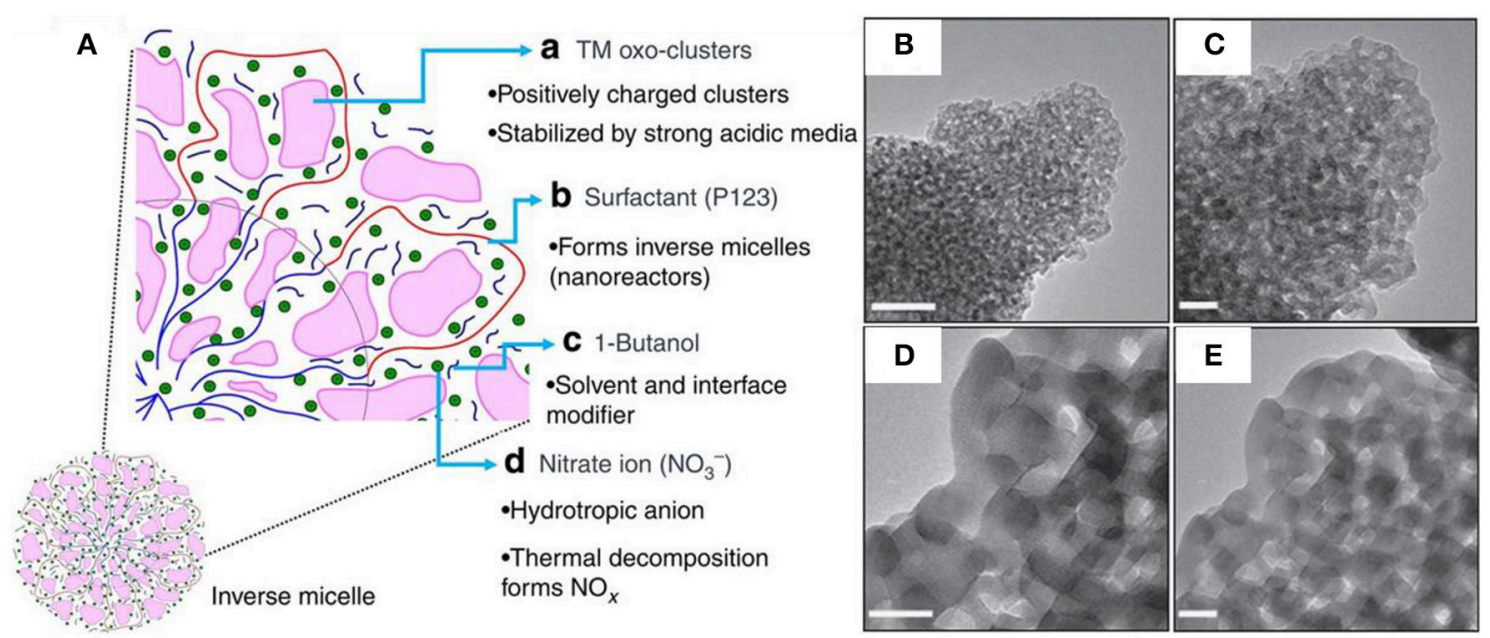

FIGURE 4 | (A) The synthetic mechanism scheme of $m$-TMOs using the inverse sol-gel method. (B-E) HR-TEM images of mesoporous $\mathrm{MnO}_{2}$ at different calcination temperature: (B,C) $150^{\circ} \mathrm{C}$ and $\mathbf{( D , E )} 550^{\circ} \mathrm{C}$. Scale bars are $20 \mathrm{~nm}$. Reprinted with permission from Poyraz et al. (2013) Copyright 2013 Nature Publishing Group.

(a)

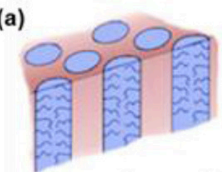

Hexagonally arranged polymer-metal oxide hybrid

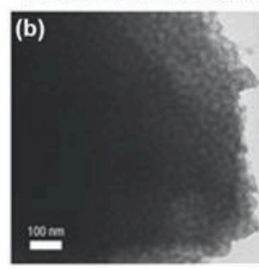

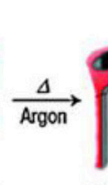

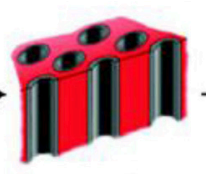

Highly crystalline metal oxide-carbon composite

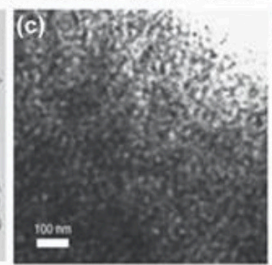

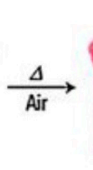

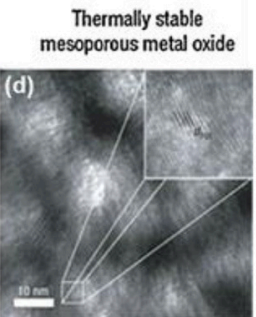

FIGURE 5 | (a) Schematic illustration of combined assembly by soft and hard (CASH) method. TEM images of (b) as-made $\mathrm{PI}-b-\mathrm{PEO} / \mathrm{TiO} 2$ hybrids, (c) the $\mathrm{TiO}_{2}-\mathrm{C}$ composite after heat treatment under argon, and (d) the resultant $m-\mathrm{TiO}_{2}$ after removal of the carbon after calcination in air. Reprinted with permission from Lee et al. (2008). Copyright 2008 Nature Publishing Group. mesoporous $\mathrm{TiO}_{2}$ obtained in this method is stable up to $700^{\circ} \mathrm{C}$; and it has a specific surface area of $122 \mathrm{~m}^{2} \mathrm{~g}^{-1}$ and a pore size of $10 \mathrm{~nm}$.

\section{COLLOIDAL-TEMPLATING METHOD}

The examples highlighted in the soft-templating method share a key idea, i.e., to improve the stability of hydrocarbon-based polymer templates and to confine the crystal growth during thermal treatment. Even though the carbonization of polymer templates enhances thermal stability, it is limited to some extent. The carbonized polymer templates require the thermal annealing with extra caution, for example, under inert gas atmosphere and without extremely long annealing time. Otherwise, the

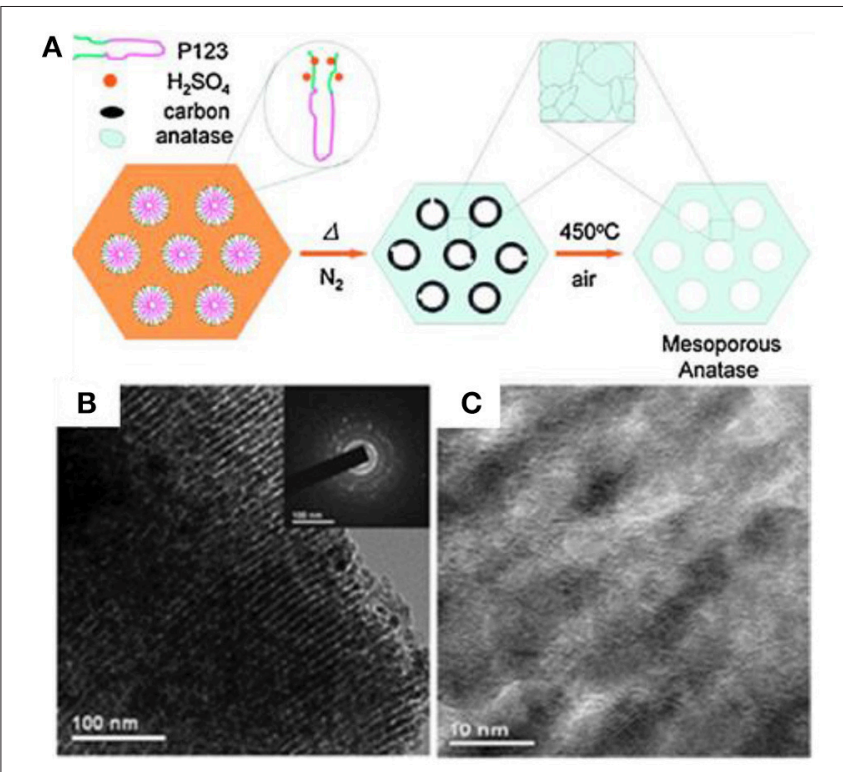

FIGURE 6 | (A) Scheme showing the sulfuric acid carbonization method for the synthesis of $m-\mathrm{TiO}_{2}$. (B, C) TEM images of $m-\mathrm{TiO}_{2}$ prepared by the surfactant sulfuric acid carbonization method after calcinating at $650^{\circ} \mathrm{C}$ in $\mathrm{N}_{2}$. Reprinted with permission from Zhang et al. (2010). Copyright 20 Willey VCH.

carbonized polymer templates can be oxidized, further resulting in the collapse of porous frameworks.

One ultimate solution to the thermal stability of templates is to introduce inorganic components, including inorganic nanoparticles (NPs) or non-hydrocarbon-based elements to polymer templates. Inorganic NPs have an inherently much higher thermal stability compared to organic polymers, while some of non-hydrocarbon-based elements, e.g., Si, can convert into inorganic oxides that are known to be thermally stable 
as well. By coupling inorganic templates with polymers, the advantages from soft-templating and hard-templating methods can be said to emerge as the "colloidal-templating" method. Colloidal templates are composed of an inorganic NP core tethered with flexible polymer tails. In view of the topology of colloidal templates, they are extremely like polymer micelles, which have been used in the soft-templating method to grow mesoporous materials (Bastakoti et al., 2014, 2016; Jiang et al., 2017, 2018; Tanaka et al., 2018). In the colloidaltemplating method, polymers as soft templates are responsible for coordinating inorganic metal ions to self-assemble into nanostructures, similar to that of the soft-templating method. The inorganic NPs, on the other hand, serve as hard templates to offer thermal stability and nanoconfinement to crystallize the framework under high-temperature annealing. Colloidal templates similar to the surfactants/block copolymers can form periodically ordered nanostructures in the course of sol-gel to fabricate mesoporous materials.

One example of colloidal templates by Dong et al. is to synthesize mesoporous graphene using oleic acid (OA)-capped $\mathrm{Fe}_{3} \mathrm{O}_{4}$ nanocrystals (Jiao et al., 2015). The self-assembled OAcapped $\mathrm{Fe}_{3} \mathrm{O}_{4}$ first formed the ordered $3 \mathrm{D} \mathrm{Fe}_{3} \mathrm{O}_{4}$ nanocrystal superlattices. The superlattices were further calcined at $1,000^{\circ} \mathrm{C}$ under argon. As inorganic components, $\mathrm{Fe}_{3} \mathrm{O}_{4}$ nanocrystals are thermally very stable with respect to annealing, while OA can be carbonized to form continuous carbon frameworks. Followed by the removal of $\mathrm{Fe}_{3} \mathrm{O}_{4}$ nanocrystals using $\mathrm{HCl}$, the ordered mesoporous carbon was derived and then transformed into highly ordered mesoporous graphene with $f c c$ symmetric mesoporosity. However, such a colloidal template is difficult to extend to the synthesis of $m$-TMO, since mixed metal oxides can be formed under high-temperature annealing.

Organosilicate-containing colloidal templates are also utilized as soft-hard templates to synthesize highly crystalline mesoporous materials, which is largely beyond the capacity of the traditional soft-templating method. It is worth noting that the phase transition of $\mathrm{TiO}_{2}$ requires high temperature calcination $\left(>800^{\circ} \mathrm{C}\right)$. Traditional carbon-based soft templates are unlikely to be stable at such a high temperature to support the mesoporous frameworks. Our group recently developed a new series of colloidal templates consisting of a silica-containing inorganic core and PEO shell (Liu et al., 2015b). The synthesis of such colloidal templates is based on the self-assembly of amphiphilic block copolymers in water (Figure 7). Briefly, a diblock copolymer of poly(ethylene oxide)-block-poly[3(trimethoxysilyl)propyl methacrylate] (PEO- $b$-PTMSPMA) can form polymer micelles in the mixture solvent of water and ethanol. The micelles are highly uniform with an average diameter of $25 \pm 2 \mathrm{~nm}$. The hydrophobic PTMSPMA block contains trimethoxysilyl moieties that can hydrolyze to form polysilsesquioxane. Upon the addition of transition metal precursors, the coordination interaction between $\mathrm{PEO}$ and metal ions, similar to that in the soft-templating method, can result in the co-assembly of colloidal templates with metal precursors along with sol-gel transition during EISA. When annealing at high temperature, the polysilsesquioxane cores of colloidal templates further convert into rigid silica nanoparticles to

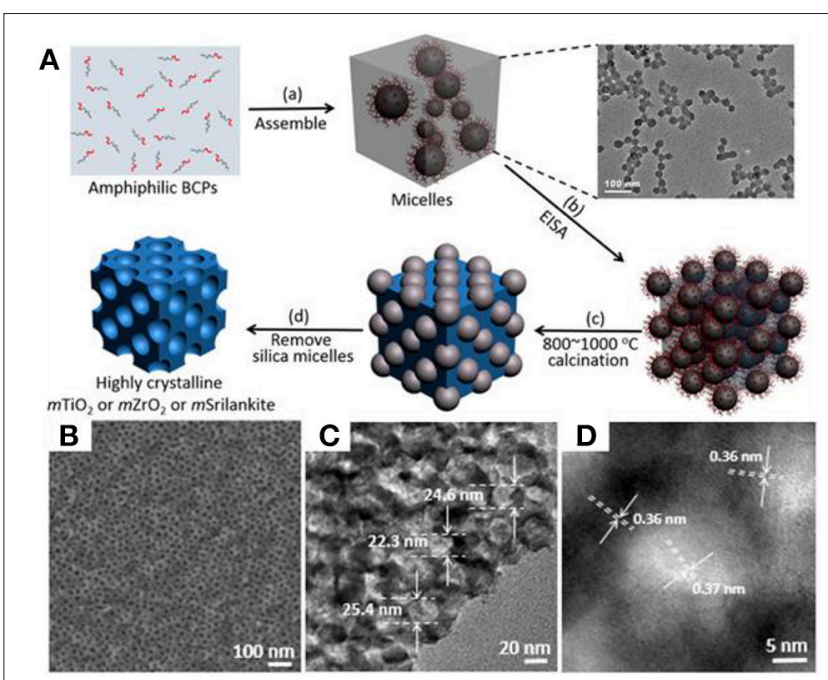

FIGURE 7 | (A) Schematic illustration of highly crystalline $m$-TMOs based on the colloidal amphiphile-templating method. (B) SEM, and (C,D) TEM images of as-resultant $m-\mathrm{TiO}_{2}$ with uniform mesopores. Reprinted with permission from Liu et al. (2015b). Copyright 2015 American Chemical Society.

support the structural integrity of the mesoporous framework, while the PEO will be burned off. Since silica is stable up to an air temperature of $1,000^{\circ} \mathrm{C}$, the porous materials can be directly annealed at $1,000^{\circ} \mathrm{C}$ without disrupting their mesostructures. Therefore, the colloidal-templating method offers an ideal solution to the disadvantages of traditional soft templates, having poor thermal stability, and low mechanical strength.

Using $m-\mathrm{TiO}_{2}$ as an example, our group demonstrated that $m$ $\mathrm{TiO}_{2}$ synthesized with colloidal templates could be recrystallized at $900^{\circ} \mathrm{C}$ under air without further pretreatment (Figure 7B). $m-\mathrm{TiO}_{2}$ has a pore size of $21 \mathrm{~nm}$ and a specific surface area of $54.5 \mathrm{~m}^{2} \mathrm{~g}^{-1}$. Importantly, calcination at $900^{\circ} \mathrm{C}$ can lead to the formation of $\mathrm{TiO}_{2}$ with mixed anatase and rutile, similar to that of $\mathrm{P} 25$. Crystallization of mesoporous $\mathrm{TiO}_{2}$ is rationally tailored by calcination temperature or time, which exhibit dramatically enhanced activity toward photocatalysis (discussed below). In addition, the colloidal-templating method can be extended to synthesize the other $m$-TMOs, such as group- $\mathrm{V} m-\mathrm{ZrO}_{2}$ and group-IV/group-V mixed transition-metal oxide, $\mathrm{Zr}_{0.33} \mathrm{Ti}_{0.67} \mathrm{O}_{2}$ ( $m$-Srilankite). In particular, highly crystalline $m-\mathrm{ZrO}_{2}$ and $m$ Srilankite with uniform pore sizes can be obtained at $800^{\circ} \mathrm{C}$.

Following the similar synthetic strategy, the colloidal templating method can used to prepare mesoporous carbon or TMO supported on carbon. To do so, the colloidal templates can template the oxidative self-polymerization of dopamine to polydopamine (PDA) nanospheres Liu et al. (2017b). In this case, the hydrogen bonds between dopamine with the PEO shell of colloidal templates drive the co-assembly. Since there are abundant functional groups (e.g., catechol and amine) of PDA to strongly coordinate metal ions (e.g., $\mathrm{Co}^{2+}$ ), the hybrids of PDA, and colloidal templates can physically absorb $\mathrm{Co}^{2+}$ ions. When annealing at $650^{\circ} \mathrm{C}$ under $\mathrm{N}_{2}$, the PDA backbone could be transformed into hierarchical porous 
carbon frameworks by pyrolysis while $\mathrm{Co}^{2+}$ ions were reduced metallic Co nanoparticles (2-7 nm) (Liu et al., 2017b). Here, the mechanically strong colloidal templates not only supported the porous carbon frameworks, but also confined the growth of Co NPs to restrain their overgrowth. Our group also extended this universal colloidal-templating method to develop a series of mesoporous hybrid nanostructures of metal-oxides and metal-carbons (Liu et al., 2016, 2017a,b, 2018).

In addition, the use of colloidal templates can bring unexpected functionalities of inorganic NP to oxides, e.g., optical and/or catalytic properties, when replacing the silica cores of the colloidal template with noble metal NPs (Joo et al., 2009). One intriguing report from Mirkin's group shows that DNA-modified Au NPs as colloidal templates can guide the synthesis of mesoporous silica (Figure 8a) (Auyeung et al., 2015). To do so, the citrate-capped $5 \mathrm{~nm} \mathrm{Au} \mathrm{NPs} \mathrm{were} \mathrm{first}$ modified by thiolated DNA sequences ( $\sim 25$ dsDNA per NP). Other DNA strands complementary to the DNA ligands on Au NPs were added into the mixture solution (1:1 ratio) of $\mathrm{Au}$ to initiate rapid aggregation. The disordered aggregates were subsequently slow-cooled from 60 to $25^{\circ} \mathrm{C}$ at a rate of $0.1^{\circ} \mathrm{C} / 10 \mathrm{~min}$ to get spatially organized $\mathrm{Au}$ superlattices. The $\mathrm{Au}$ superlattices were further utilized as templates to grow silica in the DNA domain. Upon the removal of DNA by calcination, Au NP superlattices within porous silica supports could be synthesized. Due to the confinement of silica, Au NPs have high thermal stability without sintering. The obtained hybrids show a typical Type-IV isotherm with a specific surface area of $210 \mathrm{~m}^{2} \mathrm{~g}^{-1}$ (Figures $\mathbf{8 b}, \mathbf{c}$ ). The porous Au NP superlattices with available channels are catalytically active in alcohol oxidation.

Co-assembly of two sets of colloidal templates into mesoporous materials also provides a new strategy to encapsulate functional NPs, especially noble metal NPs, within mesoporous frameworks of TMOs. Recently, two sets of colloids, including PS- $b$-PEO-tethered Au (Au-PS-PEO) and spherical colloidal of self-assembled PS- $b$-PEO, were utilized as co-templates for the growth of $\mathrm{Au} / m \mathrm{WO}_{3}$ hybrid materials (Liu et al., 2015a). The two sets of colloidal templates share similar structural and chemical features and can co-assemble during the growth and crystallization of $\mathrm{WO}_{3}$, thus resulting in the homogeneous dispersion of Au NPs within $m \mathrm{WO}_{3}$. The porous frameworks can limit the mobility of Au NPs to enhance thermal stability, while the Au NPs confined by $m$-TMOs essentially exert plasmonic enhancement for the photocatalytic performance of $m$-TMOs. More importantly, because Au NPs are pre-synthesized, this method thus paves the first way to rationally control loading sizes and amounts of noble metal NPs within mesoporous oxides. The same strategy is also extendable to encapsulate noble metal NPs within $m \mathrm{TiO}_{2} \mathrm{~m}$ (Liu et al., 2017a). Furthermore, two sets of the colloidal templates with different structural features are also successful in the formation of noble metaloxide hybrid materials. For example, Au-PEO colloids and P123 have been used as co-templates to disperse Au NPs with mesoporous silica, which exhibited dramatically enhanced thermal stability of Au NPs for the high-temperature reaction (discussed later).

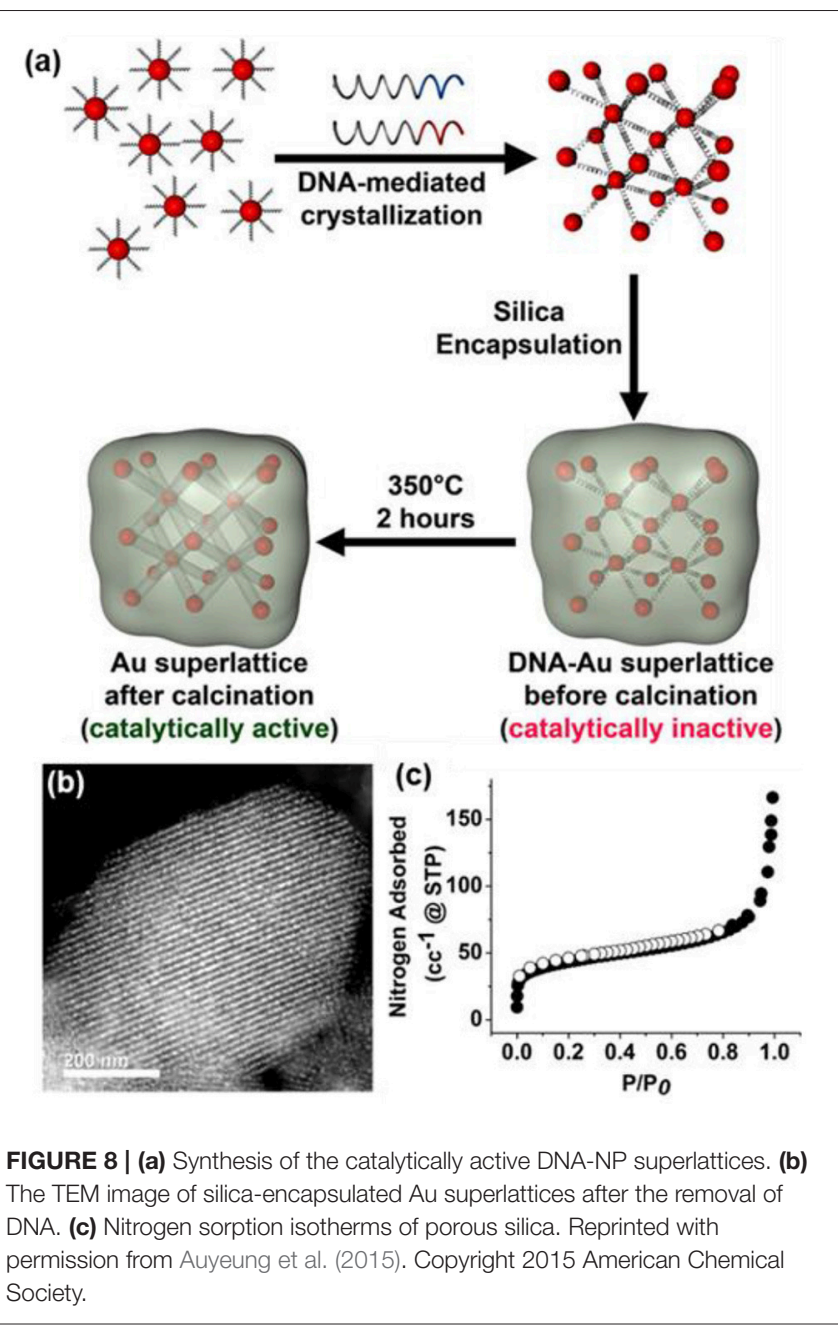

\section{APPLICATIONS}

Crystalline $m$-TMOs with high surface areas, uniform pore sizes, and accessible interspaces exhibited great potential in many applications. We highlight a few examples on the applications of $m$-TMOs synthesized via the colloidal-templating method. The first example of the application is $m-\mathrm{TiO}_{2}$ synthesized by organosilane-containing colloids for photocatalytic degradation of organic dye (Liu et al., 2015b). As discussed above, having thermally stable colloidals as the soft-hard templates renders the resultant $m-\mathrm{TiO}_{2}$ with the precisely tunable crystalline phase of anatase and rutile by tuning the calcination temperature. The percentage of anatase and rutile can be controlled by calcination temperature and annealing time. The mesoporous $\mathrm{TiO}_{2}$ obtained at $1,000^{\circ} \mathrm{C}$ for $1 \mathrm{~h}$ has $\sim 39 \%$ of rutile and $\sim 61 \%$ of anatase. In contrast, the mesoporous $\mathrm{TiO}_{2}$ obtained below $800^{\circ} \mathrm{C}$ has almost $100 \%$ anatase phase. Both crystallinity and controllable anatase/rutile interface play an important role in the enhancement of photocatalytic activity. We used the photo decomposition of organic dye (Rhodamine $\mathrm{B}, \mathrm{RhB}$ ) to evaluate the photocatalytic performance of different $\mathrm{m}$ $\mathrm{TiO}_{2}$ obtained from different calcination conditions. The 

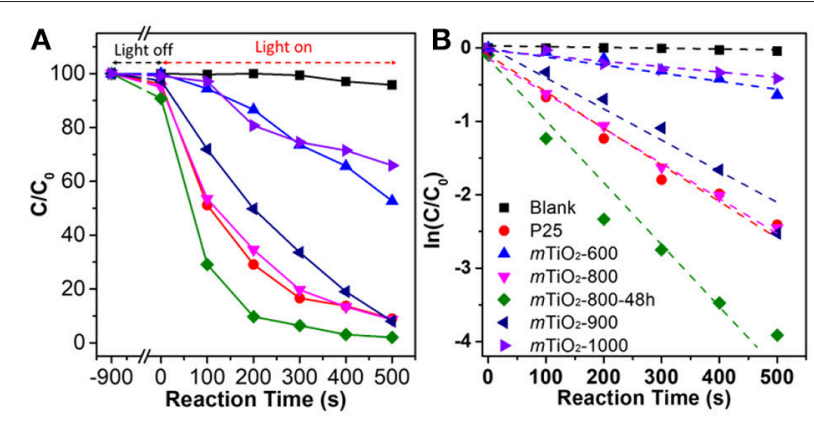

FIGURE 9 | Photocatalytic activity of $m-\mathrm{TiO}_{2}$. (A) Photocatalytic degradation of $\mathrm{RhB}$ and $(\mathbf{B})$ the fitting of the rate constant by using different mesoporous $\mathrm{TiO}_{2}\left(\mathrm{mTiO}_{2}\right)$ obtained at different calcination temperatures. Reprinted with permission from Liu et al. (2015b) Copyright 2015 American Chemical Society.

photocatalytic decomposition results of RhB were obtained from the change of absorption intensity in the corresponding UVvis spectra (Figure 9A). In addition, Figure 9B displays the kinetic fitting results by plotting $\ln \left(\mathrm{C} / \mathrm{C}_{0}\right)$ against the reaction time. The control experiment without a catalyst showed a very slow decomposition rate of $\mathrm{RhB}$, with a rate constant of 9 $\times 10^{-5} \mathrm{~s}^{-1} \cdot m-\mathrm{TiO}_{2}$ obtained at 800 and $900^{\circ} \mathrm{C}$ exhibited an increased photocatalytic activity with rate constant of 5.1 $\times 10^{-3} \mathrm{~s}^{-1}$ and $4.4 \times 10^{-3} \mathrm{~s}^{-1}$, respectively. The photodecomposition activity of $m-\mathrm{TiO}_{2}$ obtained at $800^{\circ} \mathrm{C}$ for $48 \mathrm{~h}$ with the highest activity showed 1.7 times higher than that of commercial P25. The above results indicate that the importance of mesoporous nanostructures and the interface of anatase and rutile phases for their photocatalytic activity. The change of photocatalytic activity is closely related to the crystallinity and controllable interface of anatase/rutile. The highly crystalline $m$ TMOs also can be prepared by using the CASH method (Lee et al., 2008), which decreased the defects to improve performance in photocatalysis.

The colloidal-templating method provides a new avenue to stabilize the noble metal NPs within a mesoporous framework, especially with amorphous $\mathrm{SiO}_{2}$ as the support. Using KIT6-typed $\mathrm{SiO}_{2}$ with the framework and mesochannels smaller than the size of Au NPs could dramatically enhance the thermal stability of $\mathrm{Au}$ under high temperature, while $\mathrm{Au}$ NPs confined by mesoporous frameworks remain accessible and catalytically active (Liu et al., 2017a). We evaluated the high temperature catalytic performance of $\mathrm{Au} @ m \mathrm{SiO}_{2}$ (Figures 10A,B) for CO oxidation. As shown in Figure 10C, when the catalytic temperature reached $275^{\circ} \mathrm{C}$ (light-off temperature), the $\mathrm{CO}$ conversion of $\mathrm{mSiO}_{2}-\mathrm{AuNP}$ hybrids show catalytic activity for CO oxidation and achieved $100 \%$ of $\mathrm{CO}$ conversion at $400^{\circ} \mathrm{C}$. In contrast, $m \mathrm{SiO}_{2}$ without $\mathrm{Au}$ NPs showed no $\mathrm{CO}$ oxidation activity even at $450^{\circ} \mathrm{C}$. The high temperature stability of $m \mathrm{SiO}_{2}$-AuNP hybrids is further investigated in Figure 10D. No decrease in activity was observed for more than $130 \mathrm{~h}$ of continuous operation, indicating that $m \mathrm{SiO}_{2}$-AuNP hybrid catalysts have outstanding stability under high temperature. Not only the mesoporous structure of
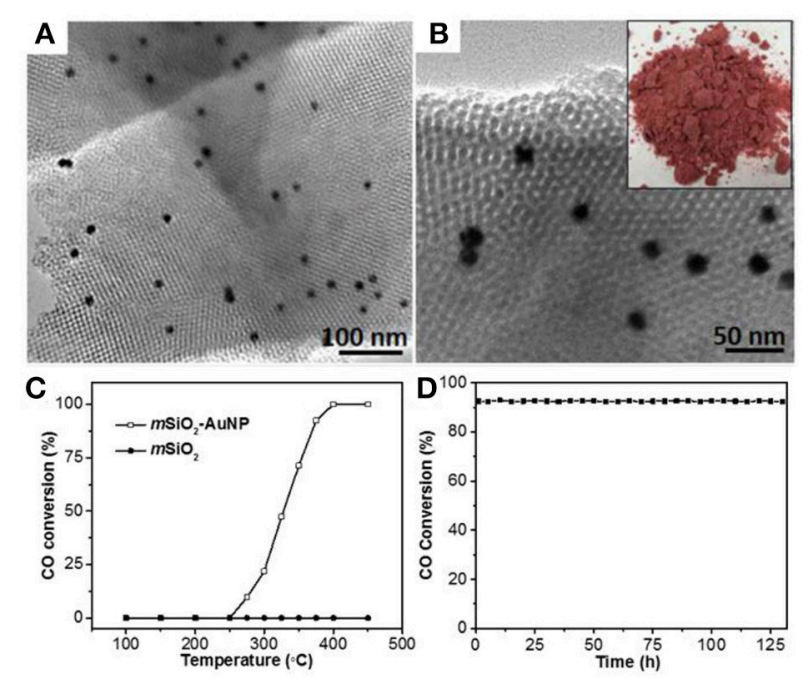

FIGURE 10 | (A,B) TEM images of Au@mSiO 2 . The size of Au NPs is 14 nm. (C) High-temperature $\mathrm{CO}$ oxidation performance of mesoporous $\mathrm{SiO}_{2}\left(\mathrm{mSiO}_{2}\right)$ and mesoporous $\mathrm{SiO}_{2}$ with $1 \%$ loading of $14 \mathrm{~nm}$ Au NPs

( $m \mathrm{SiO}_{2}$-AuNP14-1\%). (D) Durability test of $\mathrm{CO}$ oxidation with

$m \mathrm{SiO}_{2}-\mathrm{AuNP} 14-1 \%$ at $375^{\circ} \mathrm{C}$ over $130 \mathrm{~h}$. Reprinted with permission from Liu et al. (2017a). Copyright 2010 Royal Society of Chemistry.

$\mathrm{Au} @ m \mathrm{SiO}_{2}$, but also Au NPs displayed extraordinary stability after CO oxidation for $130 \mathrm{~h}$, further indicating the superior thermal stability of $\mathrm{Au}$ endowed by the nanoconfinement effect of mesoporous oxide supports. Moreover, these mesoporous metal-oxide hybrids are also potentially useful for other high temperature catalysis such as the oxidation of methane to methanol (Agarwal et al., 2017; Williams et al., 2018).

\section{SUMMARY AND PERSPECTIVES}

Advances in the rational design and formation of highly crystalline $m$-TMOs with controlled crystallinity and functions largely broaden their practical applications in catalysis and energy storage/conversion. The development of new synthetic methods is the key for all those applications. In this review, we summarize the current synthetic methodologies of $\mathrm{m}$ TMOs, including soft-templating, hard-templating, and colloidal-templating methods, and briefly discuss their advantages/disadvantages for the synthesis of $m$-TMOs. Special focus is given to the colloidal-templating synthesis of $m$-TMOs and hybrid materials of porous metal-oxides, beyond the capability of other traditional synthetic methods. Several typical examples are provided to highlight the potential applications of $m$-TMOs and porous metal-oxides synthesized by colloidal-templating method.

Despite much progress made in the synthesis of crystalline $m$-TMOs, there are still unmet synthetic challenges, particularly for the colloidal-templating method. First, no example has been documented on crystalline perovskites using soft-templating or 
colloidal-templating methods. Perovskites, as a complex oxide consisting of two or more simple oxides, have a cubic structure with a general formula of $\mathrm{ABO}_{3}$; and they have been studied extensively due to the interesting electronic and catalytic activity, e.g., as a solid electrolyte (Zhou et al., 2016) and cathode materials for fuel cells (Skinner, 2001; Suntivich et al., 2011). The synthesis of perovskites usually relies on the solid-state annealing of the mixture of oxides at $>700^{\circ} \mathrm{C}$ (Zhu et al., 2014). Because of the slow diffusion in solid states, the synthesis of perovskites can take a few hours to days to anneal the oxide mixtures. With the new CASH or organosilicate-containing colloidal-templating methods, it will be of interest to extend the current synthetic capacity to crystalline perovskites. Secondly, encapsulating noble metal NPs within highly crystalline $m$-TMOs is also unresolved. There is an extensive literature on the strong metal-oxide interaction (Tauster, 1987; Farmer and Campbell, 2010), known to be critical for catalytic activity of metal-oxide hybrids. The formation of the strong metal-oxide interaction (or strong metal-support interaction, SMSI) requires the annealing under reductive atmosphere. Control of metal-oxide interaction in the context of mesoporous hybrids has rarely been reported in previous research. In addition, we expect that more achievements

\section{REFERENCES}

Agarwal, N., Freakley, S. J., Mcvicker, R. U., Althahban, S. M., Dimitratos, N., He, Q., et al. (2017). Aqueous Au-Pd colloids catalyze selective $\mathrm{CH} 4$ oxidation to $\mathrm{CH} 3 \mathrm{OH}$ with $\mathrm{O} 2$ under mild conditions. Science 358, 223-227. doi: 10.1126/science. aan 6515

Antonelli, D. M. (1999). Synthesis and mechanistic studies of sulfated meso- and microporous zirconias with chelating carboxylate surfactants. Adv. Mater. 11, 487-492. doi: 10.1002/(SICI)1521-4095(199904)11:6<487::AID-ADMA487>3.0.CO;2-2

Antonelli, D. M., Nakahira, A., and Ying, J. Y. (1996). Ligand-assisted liquid crystal templating in mesoporous niobium oxide molecular sieves. Inorg. Chem. 35, 3126-3136. doi: 10.1021/ic951533p

Antonelli, D. M., and Ying, J. Y. (1995). Synthesis of hexagonally packed mesoporous $\mathrm{TiO}_{2}$ by a modified sol-gel method. Angew. Chem. Int. Ed. 34, 2014-2017. doi: 10.1002/anie.199520141

Auyeung, E., Morris, W., Mondloch, J. E., Hupp, J. T., Farha, O. K., and Mirkin, C. A. (2015). Controlling structure and porosity in catalytic nanoparticle superlattices with DNA. J. Am. Chem. Soc. 137, 1658-1662. doi: 10.1021/ja512116p

Bastakoti, B. P., Ishihara, S., Leo, S. Y., Ariga, K., Wu, K. C., and Yamauchi, Y. (2014). Polymeric micelle assembly for preparation of large-sized mesoporous metal oxides with various compositions. Langmuir 30, 651-659. doi: 10.1021/la403901x

Bastakoti, B. P., Li, Y., Guragain, S., Pramanik, M., Alshehri, S. M., Ahamad, T., et al. (2016). Synthesis of mesoporous transition-metal phosphates by polymeric micelle assembly. Chem. Eur. J. 22, 7463-7467. doi: 10.1002/chem.201600435

Burke, M. S., Enman, L. J., Batchellor, A. S., Zou, S., and Boettcher, S. W. (2015). Oxygen evolution reaction electrocatalysis on transition metal oxides and (Oxy)hydroxides: activity trends and design principles. Chem. Mater. 27, 7549-7558. doi: 10.1021/acs.chemmater. 5 b03148

Chen, S.-J., Li, L.-H., Chen, X.-T., Xue, Z., Hong, J.-M., and You, X.Z. (2003). Preparation and characterization of nanocrystalline zinc oxide by a novel solvothermal oxidation route. J. Cryst. Growth. 252, 184-189. doi: $10.1016 /$ S0022-0248(02)02495-8 from other fields, including macromolecules, electronics, and biomedical, can be incorporated in further developments of the synthesis and applications of $m$-TMOs. For example, new colloidal templates with different topologies assembled from different amphiphilic block copolymers (Yao et al., 2015) can add more structural hierarchies to crystalline $m$-TMOs. The interdisciplinary aspects that bring the new knowledge across fields will create new opportunities in solving those synthetic challenges.

\section{AUTHOR CONTRIBUTIONS}

All authors listed have made a substantial, direct and intellectual contribution to the work, and approved it for publication.

\section{ACKNOWLEDGMENTS}

$\mathrm{JH}$ is grateful for financial support from the National Science Foundation (CBET-1705566) and the University of Connecticut. BL is grateful for support from the Jiangsu Specially Appointed Professor plan and the Natural Science Foundation of Jiangsu Province (No. BK20180723).

Cong, S., and Xu, Y. (2011). Explaining the high photocatalytic activity of a mixed phase $\mathrm{TiO}_{2}$ : a combined effect of $\mathrm{O}_{2}$ and crystallinity. J. Phys. Chem. C 115, 21161-21168. doi: 10.1021/jp2055206

Crepaldi, E. L., Soler-Illia, G. J., Grosso, D., Cagnol, F., Ribot, F., and Sanchez, C. (2003). Controlled formation of highly organized mesoporous titania thin films: from mesostructured hybrids to mesoporous nanoanatase $\mathrm{TiO}_{2}$. J. Am. Chem. Soc. 125, 9770-9786. doi: 10.1021/ja $030070 \mathrm{~g}$

Fan, J., Yu, C., Gao, F., Lei, J., Tian, B., Wang, L., et al. (2003). Cubic mesoporous silica with large controllable entrance sizes and advanced adsorption properties. Angew. Chem. In. Ed. 42, 3146-3150. doi: 10.1002/anie.200351027

Fan, J., Yu, C., Lei, J., Zhang, Q., Li, T., Tu, B., et al. (2005). Low-temperature strategy to synthesize highly ordered mesoporous silicas with very large pores. J. Am. Chem. Soc. 127, 10794-10795. doi: 10.1021/ja052619c

Fang, Y., Lv, Y., Gong, F., Elzatahry, A. A., Zheng, G., and Zhao, D. (2016). Synthesis of 2D-mesoporous-carbon/MoS2 heterostructures with welldefined interfaces for high-performance lithium-ion batteries. Adv. Mater. 28, 9385-9390. doi: 10.1002/adma.201602210

Farmer, J. A., and Campbell, C. T. (2010). Ceria maintains smaller metal catalyst particles by strong metal-support bonding. Science 329, 933-936. doi: 10.1126/science.1191778

Fu, S., Zhu, C., Song, J., Engelhard, M. H., Li, X., Du, D., et al. (2016). Highly ordered mesoporous bimetallic phosphides as efficient oxygen evolution electrocatalysts. ACS Ener. Lett. 1, 792-796. doi: 10.1021/acsenergylett.6b00408

Grosso, D., De, A. A., Soler-Illia, G. J., Babonneau, F., Sanchez, C., Albouy, P.-A., et al. (2001). Highly organized mesoporous titania thin films showing mono-oriented 2D hexagonal channels. Adv. Mater. 13, 1085-1090. doi: 10.1002/1521-4095(200107)13:14<1085::AID-ADMA1085>3.0.CO;2-Q

$\mathrm{Gu}, \mathrm{D}$., and Schuth, F. (2014). Synthesis of non-siliceous mesoporous oxides. Chem. Soc. Rev. 43, 313-344. doi: 10.1039/C3CS60155B

Han, L., and Che, S. (2013). Anionic surfactant templated mesoporous silicas (AMSs). Chem. Soc. Rev. 42, 3740-3752. doi: 10.1039/C2CS35297D

Huo, Q., Margolese, D. I., Ciesla, U., Feng, P., Gier, T. E., Sieger, P., et al. (1994). Generalized synthesis of periodic surfactant/inorganic composite materials. Nature 368:317-321. doi: 10.1038/368317a0

Jiang, B., Guo, Y., Kim, J., Whitten, A. E., Wood, K., Kani, K., et al. (2018). Mesoporous metallic iridium nanosheets. J. Am. Chem. Soc. 140, 12434-12441. doi: $10.1021 /$ jacs.8b05206 
Jiang, B., Li, C., Dag, O., Abe, H., Takei, T., Imai, T., et al. (2017). Mesoporous metallic rhodium nanoparticles. Nat. Commun. 8:15581. doi: $10.1038 /$ ncomms 15581

Jiang, T., Poyraz, A. S., Iyer, A., Zhang, Y., Luo, Z., Zhong, W., et al. (2015). Synthesis of mesoporous iron oxides by an inverse micelle method and their application in the degradation of orange II under visible light at neutral $\mathrm{pH}$. J. Phys. Chem. C 119, 10454-10468. doi: 10.1021/acs.jpcc.5b02057

Jiao, F., and Bruce, P. G. (2007). Mesoporous crystalline $\beta-\mathrm{MnO}_{2}-\mathrm{a}$ reversible positive electrode for rechargeable lithium batteries. Adv. Mater. 19, 657-660. doi: 10.1002/adma.200602499

Jiao, F., Harrison, A., Hill, A. H., and Bruce, P. G. (2007). Mesoporous $\mathrm{Mn}_{2} \mathrm{O}_{3}$ and $\mathrm{Mn}_{3} \mathrm{O}_{4}$ with crystalline walls. Adv. Mater. 19, 4063-4066. doi: 10.1002/adma.200700336

Jiao, F., Harrison, A., Jumas, J.-C., Chadwick, A. V., Kockelmann, W., and Bruce, P. G. (2006). Ordered mesoporous $\mathrm{Fe}_{2} \mathrm{O}_{3}$ with crystalline walls. J. Am. Chem. Soc. 128, 5468-5474. doi: 10.1021/ja0584774

Jiao, F., Hill, A. H., Harrison, A., Berko, A., Chadwick, A. V., and Bruce, P. G. (2008). Synthesis of ordered mesoporous $\mathrm{NiO}$ with crystalline walls and a bimodal pore size distribution. J. Am. Chem. Soc. 130, 5262-5266. doi: $10.1021 / j a 710849 r$

Jiao, F., Shaju, K. M., and Bruce, P. G. (2005a). Synthesis of nanowire and mesoporous low-temperature $\mathrm{LiCoO} 2$ by a post-templating reaction. Angew. Chem. Int. Ed. 44, 6550-6553. doi: 10.1002/anie.200501663

Jiao, K., Zhang, B., Yue, B., Ren, Y., Liu, S., Yan, S., et al. (2005b). Growth of porous single-crystal $\mathrm{Cr}_{2} \mathrm{O}_{3}$ in a 3-D mesopore system. Chem. Commun. 5618-5620. doi: 10.1039/b512080b

Jiao, Y., Han, D., Liu, L., Ji, L., Guo, G., Hu, J., et al. (2015). Highly ordered mesoporous few-layer graphene frameworks enabled by $\mathrm{Fe}_{3} \mathrm{O}_{4}$ nanocrystal superlattices. Angew. Chem. Int. Ed. 54, 5727-5731. doi: 10.1002/anie.201501398

Jin, L., Liu, B., Wu, Y., Thanneeru, S., and He, J. (2017). Synthesis of mesoporous $\mathrm{CoS}_{2}$ and $\mathrm{Ni}_{\mathrm{x}} \mathrm{Co}_{1-\mathrm{x}} \mathrm{S}_{2}$ with superior supercapacitive performance using a facile solid-phase sulfurization. ACS App. Mater. Interfaces 9, 36837-36848. doi: 10.1021/acsami.7b11453

Joo, J. B., Dahl, M., Li, N., Zaera, F., and Yin, Y. (2013). Tailored synthesis of mesoporous $\mathrm{TiO}_{2}$ hollow nanostructures for catalytic applications. Energy Environ. Sci. 6, 2082-2092. doi: 10.1039/c3ee41155a

Joo, S. H., Park, J. Y., Tsung, C. K., Yamada, Y., Yang, P., and Somorjai, G. A. (2009). Thermally stable Pt/mesoporous silica core-shell nanocatalysts for high-temperature reactions. Nat. Mater. 8, 126-131. doi: 10.1038/nmat2329

Kanan, D. K., and Carter, E. A. (2012). Band gap engineering of $\mathrm{MnO}$ via $\mathrm{ZnO}$ alloying: a potential new visible-light photocatalyst. J. Phys. Chem. C 116, 9876-9887. doi: 10.1021/jp300590d

Kanan, D. K., and Carter, E. A. (2013). Ab initio study of electron and hole transport in pure and doped $\mathrm{MnO}$ and $\mathrm{MnO}: \mathrm{ZnO}$ alloy. J. Mater. Chem. A 1:9246. doi: $10.1039 / \mathrm{c} 3$ ta11265a

Kawahara, T., Konishi, Y., Tada, H., Tohge, N., Nishii, J., and Ito, S. (2002). A patterned $\mathrm{TiO}_{2}$ (Anatase)/ $/ \mathrm{TiO}_{2}$ (Rutile) bilayertype photocatalyst: effect of the anatase/rutile junction on the photocatalytic activity. Angew. Chem. Int. Ed. 41, 2811-2813. doi: 10.1002/1521-3773(20020802)41:15<2811::AID-ANIE2811>3.0.CO;2-\#

Kleitz, F., Hei Choi, S., and Ryoo, R. (2003). Cubic Ia3d large mesoporous silica: synthesis and replication to platinum nanowires, carbon nanorods and carbon nanotubesElectronic supplementary information (ESI) available: TEM images of mesoporous cubic silica and Pt networks, XRD patterns during formation of the cubic phase. Chem. Commun. 2136-2137. doi: 10.1039/b306504a

Kondo, J. N., and Domen, K. (2008). Crystallization of mesoporous metal oxides. Chem. Mater. 20, 835-847. doi: 10.1021/cm702176m

Kresge, C. T., Leonowicz, M. E., Roth, W. J., Vartuli, J. C., and Beck, J. S. (1992). Ordered mesoporous molecular sieves synthesized by a liquid-crystal template mechanism. Nature 359:710-712. doi: 10.1038/359710a0

Kuo, C.-H., Mosa, I. M., Poyraz, A. S., Biswas, S., El-Sawy, A. M., Song, W., et al. (2015). Robust mesoporous manganese oxide catalysts for water oxidation. ACS Catal. 5, 1693-1699. doi: 10.1021/cs501739e

Le, Z., Liu, F., Nie, P., Li, X., Liu, X., Bian, Z., et al. (2017). Pseudocapacitive sodium storage in mesoporous single-crystal-like $\mathrm{TiO} 2$-graphene nanocomposite enables high-performance sodium-ion capacitors. ACS Nano 11, 2952-2960. doi: 10.1021 /acsnano.6b08332
Lee, J., Orilall, M. C., Warren, S. C., Kamperman, M., Disalvo, F. J., and Wiesner, U. (2008). Direct access to thermally stable and highly crystalline mesoporous transition-metal oxides with uniform pores. Nat. Mater. 7, 222-228. doi: 10.1038/nmat2111

Li, H., Bian, Z., Zhu, J., Huo, Y., Li, H., and Lu, Y. (2007). Mesoporous Au/TiO2 nanocomposites with enhanced photocatalytic activity. J. Am. Chem. Soc. 129, 4538-4539. doi: 10.1021/ja069113u

Li, J., Wang, Y., Tang, J., Wang, Y., Wang, T., Zhang, L., et al. (2015). Direct growth of mesoporous carbon-coated Ni nanoparticles on carbon fibers for flexible supercapacitors. J. Mater. Chem. A 3, 2876-2882. doi: 10.1039/C4TA 05668J

Li, W., Liu, J., and Zhao, D. (2016). Mesoporous materials for energy conversion and storage devices. Nat. Rev. Mater. 1:16023. doi: 10.1038/natrevmats.2016.23

Li, W., Wu, Z., Wang, J., Elzatahry, A. A., and Zhao, D. (2013). A perspective on mesoporous $\mathrm{TiO} 2$ materials. Chem. Mater. 26, 287-298. doi: $10.1021 / \mathrm{cm} 4014859$

Liang, C., Li, Z., and Dai, S. (2008). Mesoporous carbon materials: synthesis and modification. Angew. Chem. 47,3696-3717. doi: 10.1002/anie.200702046

Liu, B., Jiang, T., Zheng, H., Dissanayke, S., Song, W., Federico, A., et al. (2017a). Nanoengineering of aggregation-free and thermally-stable gold nanoparticles in mesoporous frameworks. Nanoscale 9, 6380-6390. doi: 10.1039/C7NR01988B

Liu, B., Jin, L., Zheng, H., Yao, H., Wu, Y., Lopes, A., et al. (2017b). Ultrafine co-based nanoparticle@mesoporous carbon nanospheres toward high-performance supercapacitors. ACS App. Mater. Interfaces 9, 1746-1758. doi: 10.1021/acsami.6b11958

Liu, B., Kuo, C. H., Chen, J., Luo, Z., Thanneeru, S., Li, W., et al. (2015a). Ligand-assisted co-assembly approach toward mesoporous hybrid catalysts of transition-metal oxides and noble metals: photochemical water splitting. Angew. Chem. Int. Ed. 54, 9061-9065. doi: 10.1002/anie.201502892

Liu, B., Louis, M., Jin, L., Li, G., and He, J. (2018). Co-template directed synthesis of gold nanoparticles in mesoporous titanium dioxide. Chem. Eur. J. 24 9651-9657. doi: 10.1002/chem.201801223

Liu, B., Luo, Z., Federico, A., Song, W., Suib, S. L., and He, J. (2015b). Colloidal amphiphile-templated growth of highly crystalline mesoporous nonsiliceous oxides. Chem. Mater. 27, 6173-6176. doi: 10.1021/acs.chemmater.5b02248

Liu, B., Yao, H., Daniels, R. A., Song, W., Zheng, H., Jin, L., et al. (2016). A facile synthesis of Fe3C@mesoporous carbon nitride nanospheres with superior electrocatalytic activity. Nanoscale 8, 5441-5445. doi: 10.1039/C6NR0 $0604 \mathrm{C}$

Liu, P., Moudrakovski, I. L., Liu, J., and Sayari, A. (1997). Mesostructured vanadium oxide containing dodecylamine. Chem. Mater. 9, 2513-2520. doi: $10.1021 / \mathrm{cm} 970067 \mathrm{u}$

Lokupitiya, H. N., Jones, A., Reid, B., Guldin, S., and Stefik, M. (2016). Ordered mesoporous to macroporous oxides with tunable isomorphic architectures: solution criteria for persistent micelle templates. Chem. Mater. 28, 1653-1667. doi: 10.1021/acs.chemmater.5b04407

Lu, A.-H., Schmidt, W., Taguchi, A., Spliethoff, B., Tesche, B., and Schüth, F. (2002). Taking nanocasting one step further: replicating CMK-3 as a silica material. Angew. Chem. Int. Ed. 41, 3489-3492. doi: 10.1002/1521-3773(20020916)41:18<3489::AID-ANIE3489>3.0.CO;2-M

Lu, A.-H., and Schüth, F. (2005). Nanocasting pathways to create ordered mesoporous solids. C. R. Chim. 8, 609-620. doi: 10.1016/j.crci.2004.10.020

Lu, A. H., and Schüth, F. (2006). Nanocasting: a versatile strategy for creating nanostructured porous materials. Adv. Mater. 18, 1793-1805. doi: 10.1002/adma.200600148

Lu, H., Zhang, P., Qiao, Z. A., Zhang, J., Zhu, H., Chen, J., et al. (2015). Ionic liquid-mediated synthesis of meso-scale porous lanthanum-transitionmetal perovskites with high CO oxidation performance. Chem. Commun. 51, 5910-5913. doi: 10.1039/C5CC00534E

Meng, Y., Gu, D., Zhang, F., Shi, Y., Yang, H., Li, Z., et al. (2005). Ordered mesoporous polymers and homologous carbon frameworks: amphiphilic surfactant templating and direct transformation. Angew. Chem. Int. Ed. 44, 7053-7059. doi: 10.1002/anie.200501561

Miyagi, T., Kamei, M., Mitsuhashi, T., Ishigaki, T., and Yamazaki, A. (2004). Charge separation at the rutile/anatase interface: a dominant factor of photocatalytic activity. Chem. Phys. Lett. 390, 399-402. doi: 10.1016/j.cplett.2004.04.042 
Ohtani, B., Ogawa, Y., and Nishimoto, S.-I. (1997). Photocatalytic activity of amorphous-anatase mixture of titanium(IV) oxide particles suspended in aqueous solutions. J. Phys. Chem. C 101, 3746-3752. doi: 10.1021/jp962702+

Onozuka, K., Kawakami, Y., Imai, H., Yokoi, T., Tatsumi, T., and Kondo, J. N. (2012). Perovskite-type La2Ti2O7 mesoporous photocatalyst. J. Solid States Chem. 192, 87-92. doi: 10.1016/j.jssc.2012.03.055

Polarz, S., Orlov, A. V., Schuth, F., and Lu, A. H. (2007). Preparation of high-surface-area zinc oxide with ordered porosity, different pore sizes, and nanocrystalline walls. Chem. Eur. J. 13, 592-597. doi: 10.1002/chem.200600428

Poyraz, A. S., Kuo, C.-H., Kim, E., Meng, Y., Seraji, M. S., and Suib, S. L. (2014). Tungsten-promoted mesoporous group 4 (Ti, Zr, and Hf) transitionmetal oxides for room-temperature solvent-free acetalization and ketalization reactions. Chem. Mater. 26, 2803-2813. doi: 10.1021/cm501216c

Poyraz, A. S., Kuo, C. H., Biswas, S., King'ondu, C. K., and Suib, S. L. (2013). A general approach to crystalline and monomodal pore size mesoporous materials. Nat. Commun. 4:2952. doi: 10.1038/ncomms3952

Qiu, H., and Che, S. (2011). Chiral mesoporous silica: chiral construction and imprinting via cooperative self-assembly of amphiphiles and silica precursors. Chem. Soc. Rev. 40, 1259-1268. doi: 10.1039/C0CS00002G

Ren, Y., Armstrong, A. R., Jiao, F., and Bruce, P. G. (2010). Influence of size on the rate of mesoporous electrodes for lithium batteries. J. Am. Chem. Soc. 132, 996-1004. doi: 10.1021/ja905488x

Ren, Y., Ma, Z., and Bruce, P. G. (2012). Ordered mesoporous metal oxides: synthesis and applications. Chem. Soc. Rev. 41, 4909-4927. doi: $10.1039 / \mathrm{c} 2 \operatorname{cs} 35086 \mathrm{f}$

Ren, Y., Ma, Z., Morris, R. E., Liu, Z., Jiao, F., Dai, S., et al. (2013). A solid with a hierarchical tetramodal micro-meso-macro pore size distribution. Nat. Commun. 4:2015. doi: 10.1038/ncomms3015

Ren, Y., Ma, Z., Qian, L., Dai, S., He, H., and Bruce, P. G. (2009). Ordered crystalline mesoporous oxides as catalysts for CO oxidation. Catal. Lett. 131, 146-154. doi: 10.1007/s10562-009-9931-0

Roggenbuck, J., and Tiemann, M. (2005). Ordered mesoporous magnesium oxide with high thermal stability synthesized by exotemplating using CMK-3 carbon. J. Am. Chem. Soc. 127, 1096-1097. doi: 10.1021/ja043605u

Sakamoto, Y., Kaneda, M., Terasaki, O., Zhao, D. Y., Kim, J. M., Stucky, G., et al. (2000). Direct imaging of the pores and cages of three-dimensional mesoporous materials. Nature 408,449-453. doi: 10.1038/35044040

Scanlon, D. O., Dunnill, C. W., Buckeridge, J., Shevlin, S. A., Logsdail, A. J., Woodley, S. M., et al. (2013). Band alignment of rutile and anatase $\mathrm{TiO}(2)$. Nat. Mater. 12, 798-801. doi: 10.1038/nmat3697

Schüth, F. (2001). Non-siliceous mesostructured and mesoporous materials. Chem. Mater. 13, 3184-3195. doi: 10.1021/cm011030j

Siah, W. R., Lintang, H. O., Shamsuddin, M., and Yuliati, L. (2016). High photocatalytic activity of mixed anatase-rutile phases on commercial TiO2nanoparticles. Mater. Sci. Eng. 107:012005. doi: 10.1088/1757-899X/107/1/012005

Skinner, S. J. (2001). Recent advances in Perovskite-type materials for solid oxide fuel cell cathodes. J. Inorg. Mater. 3, 113-121. doi: 10.1016/S1466-6049(01)00004-6

Song, F., Bai, L., Moysiadou, A., Lee, S., Hu, C., Liardet, L., et al. (2018). Transition metal oxides as electrocatalysts for the oxygen evolution reaction in alkaline solutions: an application-inspired renaissance. J. Am. Chem. Soc. 140, 7748-7759. doi: 10.1021/jacs.8b04546

Song, M. S., Nahm, S., Cho, W. I., and Lee, C. (2015). Enhanced electrochemical performance of a $\mathrm{ZnO}-\mathrm{MnO}$ composite as an anode material for lithium ion batteries. Phys. Chem. Chem. Phys. 17, 23496-23502. doi: 10.1039/C5CP $03375 \mathrm{~F}$

Song, W., Poyraz, A. S., Meng, Y., Ren, Z., Chen, S.-Y., and Suib, S. L. (2014). Mesoporous $\mathrm{Co} 3 \mathrm{O} 4$ with controlled porosity: inverse micelle synthesis and high-performance catalytic $\mathrm{CO}$ oxidation at $-60^{\circ} \mathrm{C}$. Chem. Mater. 26, 4629-4639. doi: 10.1021/cm502106v

Su, H., Jaffer, S., and Yu, H. (2016). Transition metal oxides for sodiumion batteries. Energy Storg. Mater. 5, 116-131. doi: 10.1016/j.ensm.2016. 06.005

Suntivich, J., May, K. J., Gasteiger, H. A., Goodenough, J. B., and ShaoHorn, Y. (2011). A perovskite oxide optimized for oxygen evolution catalysis from molecular orbital principles. Science 334, 1383-1385. doi: $10.1126 /$ science. 1212858
Tanaka, S., Kaneti, Y. V., Bhattacharjee, R., Islam, M. N., Nakahata, R., Abdullah, N., et al. (2018). Mesoporous iron oxide synthesized using poly(styreneb-acrylic acid-b-ethylene glycol) block copolymer micelles as templates for colorimetric and electrochemical detection of glucose. ACS App. Mater. Interfaces 10, 1039-1049. doi: 10.1021/acsami.7b13835

Tauster, S. J. (1987). Strong metal-support interactions. Acc. Chem. Res. 20, 389-394. doi: 10.1021/ar00143a001

Tian, B., Liu, X., Solovyov, L. A., Liu, Z., Yang, H., Zhang, Z., et al. (2004). Facile synthesis and characterization of novel mesoporous and mesorelief oxides with gyroidal structures. J. Am. Chem. Soc. 126, 865-875. doi: 10.1021/ja037877t

Vovchok, D., Guild, C. J., Dissanayake, S., Llorca, J., Stavitski, E., Liu, Z., et al. (2018). In situ characterization of mesoporous $\mathrm{Co} / \mathrm{CeO} 2$ catalysts for the high-temperature water-gas shift. J. Phys. Chem. C 122, 8998-9008. doi: 10.1021/acs.jpcc.8b01271

Wang, Y., Yang, C.-M., Schmidt, W., Spliethoff, B., Bill, E., and Schüth, F. (2005). Weakly ferromagnetic ordered mesoporous $\mathrm{Co} 3 \mathrm{O} 4$ synthesized by nanocasting from vinyl-functionalized cubic Ia3d mesoporous silica. Adv. Mater. 17, 53-56. doi: 10.1002/adma.200400777

Wasalathanthri, N. D., Poyraz, A. S., Biswas, S., Meng, Y., Kuo, C.-H., Kriz, D. A., et al. (2015). High-performance catalytic CH4 oxidation at low temperatures: inverse micelle synthesis of amorphous mesoporous manganese oxides and mild transformation to K2-xMn8O16 and $\epsilon-\mathrm{MnO} 2$. J. Phys. Chem. C 119, 1473-1482. doi: 10.1021/jp5108558

Williams, C., Carter, J. H., Dummer, N. F., Chow, Y. K., Morgan, D. J., Yacob, S., et al. (2018). Selective oxidation of methane to methanol using supported AuPd catalysts prepared by stabilizer-free sol-immobilization. ACS Catal. 8, 2567-2576. doi: 10.1021/acscatal.7b04417

Wong, M. S., Antonelli, D. M., and Ying, J. Y. (1997). Synthesis and characterization of phosphated mesoporous zirconium oxide. Nanostruct. Mater. 9, 165-168. doi: 10.1016/S0965-9773(97)00044-5

Wu, Z., Lv, Y., Xia, Y., Webley, P. A., and Zhao, D. (2012). Ordered mesoporous platinum@graphitic carbon embedded nanophase as a highly active, stable, and methanol-tolerant oxygen reduction electrocatalyst. J. Am. Chem. Soc. 134, 2236-2245. doi: 10.1021/ja209753w

Xin, X., Qin, H., Cong, H. P., and Yu, S. H. (2018). Templating synthesis of mesoporous Fe3C-encapsulated Fe-N-doped carbon hollow nanospindles for electrocatalysis. Langmuir 34, 4952-4961. doi: 10.1021/acs.langmuir.8b00548

Yang, H., and Zhao, D. (2005). Synthesis of replica mesostructures by the nanocasting strategy. J. Mater. Chem. A 15, 1217-1231. doi: 10.1039/b414402c

Yang, P., Zhao, D., Margolese, D. I., Chmelka, B. F., and Stucky, G. D. (1998). Generalized syntheses of large-pore mesoporous metal oxides with semicrystalline frameworks. Nature 396:152-155. doi: 10.1038/24132

Yang, P., Zhao, D., Margolese, D. I., Chmelka, B. F., and Stucky, G. D. (1999). Block copolymer templating syntheses of mesoporous metal oxides with large ordering lengths and semicrystalline framework. Chem. Mater. 11, 2813-2826. doi: $10.1021 / \mathrm{cm} 990185 \mathrm{c}$

Yao, D., Chen, Y., and Jin, R. (2015). Different dimensional silica materials prepared using shaped block copolymer nanoobjects as catalytic templates. J. Mater. Chem. B 3, 5786-5794. doi: 10.1039/C5TB00589B

Yue, B., Tang, H., Kong, Z., Zhu, K., Dickinson, C., Zhou, W., et al. (2005). Preparation and characterization of three-dimensional mesoporous crystals of tungsten oxide. Chem. Phys. Lett. 407, 83-86. doi: 10.1016/j.cplett.2005.03.066

Yun, H.-S., Miyazawa, K., Zhou, H. S., Honma, I., and Kuwabara, M. (2001). Synthesis of mesoporous thin TiO2 films with hexagonal pore structures using triblock copolymer templates. Adv. Mater. 13, 1377-1380. doi: 10.1002/1521-4095(200109)13:18<1377::AID-ADMA1377>3.0.CO;2-T

Zhang, J., Deng, Y., Gu, D., Wang, S., She, L., Che, R., et al. (2011). Ligand-assisted assembly approach to synthesize large-pore ordered mesoporous titania with thermally stable and crystalline framework. Adv. Energy Mater. 1, 241-248. doi: 10.1002/aenm.201000004

Zhang, R., Tu, B., and Zhao, D. (2010). Synthesis of highly stable and crystalline mesoporous anatase by using a simple surfactant sulfuric acid carbonization method. Chem. Eur. J. 16, 9977-9981. doi: 10.1002/chem.201001241

Zhao, D., Feng, J., Huo, Q., Melosh, N., Fredrickson, G. H., Chmelka, B. F., et al. (1998a). Triblock copolymer syntheses of mesoporous silica with periodic 50 to 300 angstrom pores. Science 279, 548-552. doi: 10.1126/science.279.5350.548

Zhao, D., Huo, Q., Feng, J., Chmelka, B. F., and Stucky, G. D. (1998b). Nonionic triblock and star diblock copolymer and oligomeric surfactant syntheses of 
highly ordered, hydrothermally stable, mesoporous silica structures. J. Am. Chem. Soc. 120, 6024-6036. doi: 10.1021/ja974025i

Zhao, H., Liu, L., Andino, J. M., and Li, Y. (2013). Bicrystalline TiO2 with controllable anatase-brookite phase content for enhanced $\mathrm{CO} 2$ photoreduction to fuels. J. Mater. Chem. A 1,8209-8216.doi: 10.1039/C3TA11226H

Zheng, M., Tang, H., Li, L., Hu, Q., Zhang, L., Xue, H., et al. (2018). Hierarchically nanostructured transition metal oxides for lithium-ion batteries. Adv. Sci. 5:1700592. doi: 10.1002/advs.201700592

Zhou, W., Sun, F., Pan, K., Tian, G., Jiang, B., Ren, Z., et al. (2011). Well-ordered large-pore mesoporous anatase $\mathrm{TiO} 2$ with remarkably high thermal stability and improved crystallinity: preparation, characterization, and photocatalytic performance. Adv. Funct. Mater. 21, 1922-1930. doi: 10.1002/adfm.201002535

Zhou, Y., Guan, X., Zhou, H., Ramadoss, K., Adam, S., Liu, H., et al. (2016). Strongly correlated perovskite fuel cells. Nature 534, 231-234. doi: 10.1038/nature17653

Zhu, J., Li, H., Zhong, L., Xiao, P., Xu, X., Yang, X., et al. (2014). Perovskite oxides: preparation, characterizations, and applications in heterogeneous catalysis. ACS Catal. 4, 2917-2940. doi: 10.1021/cs500606g
Zhu, K., Yue, B., Zhou, W., and He, H. (2003). Preparation of three-dimensional chromium oxide porous single crystals templated by SBA-15. Chem. Commun. 98-99. doi: 10.1039/b210065g

Conflict of Interest Statement: The handling editor declared a shared affiliation, though no other collaboration, with the authors $\mathrm{JH}, \mathrm{LJ}$, and $\mathrm{LZ}$ at the time of review.

The remaining author declares that the research was conducted in the absence of any commercial or financial relationships that could be construed as a potential conflict of interest.

Copyright (C) 2019 Zhang, Jin, Liu and He. This is an open-access article distributed under the terms of the Creative Commons Attribution License (CC BY). The use, distribution or reproduction in other forums is permitted, provided the original author(s) and the copyright owner(s) are credited and that the original publication in this journal is cited, in accordance with accepted academic practice. No use, distribution or reproduction is permitted which does not comply with these terms. 